\title{
Multiresidue determination of estrogens in different dairy products by ultra-high-performance liquid chromatography triple quadrupole mass spectrometry ${ }^{\text {负 }}$
}

\author{
Bárbara Socas-Rodríguez ${ }^{\mathrm{a}}$, Antonio V. Herrera-Herrera ${ }^{\mathrm{b}}$, Javier Hernández-Borges ${ }^{\mathrm{a}}$, \\ Miguel Ángel Rodríguez-Delgado ${ }^{\mathrm{a}, *}$ \\ a Departamento de Química, Unidad Departamental de Química Analítica, Facultad de Ciencias, Universidad de La Laguna (ULL), Avda. Astrofísico Fco. \\ Sánchez, s/n', 38206 San Cristóbal de La Laguna, Spain \\ ${ }^{\mathrm{b}}$ Instituto Universitario de Bio-Orgánica Antonio González, Universidad de La Laguna (ULL), Avda. Astrofísico Fco. Sánchez, 2, 38206 San Cristóbal de La \\ Laguna, Spain
}

\section{A R T I C L E I N F O}

\section{Article history:}

Received 27 January 2017

Received in revised form 15 March 2017

Accepted 17 March 2017

Available online 19 March 2017

\section{Keywords:}

Estrogens

QuEChERS

Cheese

Kefir

Ultra-high-performance liquid

chromatography

Mass spectrometry

\begin{abstract}
A B S T R A C T
In this work, a simple and fast methodology has been validated and applied for the analysis of a group of 22 estrogenic compounds including eight phytoestrogens (i.e. daidzein, enterodiol, glycitein, enterolactone, genistein, formononetin, prunetin, biochanin A), six mycotoxins ( $\beta$-zearalanol, $\beta$-zearalenol, $\alpha$-zearalanol, $\alpha$-zearalenol, zearalanone, zearalenone) as well as four synthetic (i.e. ethynylestradiol, diethylstilbestrol, dienestrol, hexestrol) and four natural estrogens (i.e. estriol, $17 \beta$-estradiol, $17 \alpha-$ estradiol, estrone) in different dairy products. Extraction was carried out using the QuEChERS method while separation, determination and quantification of the target analytes were achieved by ultrahigh-performance liquid chromatography coupled to triple quadrupole mass spectrometry with an electrospray ionization interface. The methodology was validated for four dairy product samples with relevant interest for the population including skimmed and whole cheese and goat and cow kefir, using $17 \beta$-estradiol-2,4,16,16,17- $\mathrm{d}_{5}$ as internal standard for natural and synthetic estrogens and $\beta$-zeralanol$10,10,11,12,12-\mathrm{d}_{5}$ as internal standard for mycotoxins and phytoestrogens. Recovery ranged from 70 to $119 \%$ for the four types of matrices with RSD values lower than $14 \%$ and the limits of quantification of the method achieved were in the range $0.025-2.50 \mu \mathrm{g} / \mathrm{kg}$ for all samples. Finally, the analysis of commercially available products was carried out finding the presence of daidzein, glycitein enterolactone and genistein in some of the studied samples.
\end{abstract}

(c) 2017 Elsevier B.V. All rights reserved.
Abbreviations: ACN, acetonitrile; DES, diethylstilbestrol; DS, dienestrol; $\mathrm{E}_{1}$. estrone; $E_{3}$, estriol; $E_{2}$, ethynylestradiol; ESI, electrospray ionization; GC, gas chromatography; HEX, hexestrol; HF-LPME, hollow-fiber liquid-phase microextraction; IS, internal standard; IT, ion trap; LC, liquid chromatography; LLE, liquid-liquid extraction; $\mathrm{MeOH}$, methanol; MRLs, maximum residues limits; MRM, multiple reaction monitoring; MS, mass spectrometry; $\mathrm{PP}$, polypropylene; $\mathrm{QqQ}$ triple quadrupole; SPE, solid-phase extraction; UHPLC, ultra-high-performance liquid chromatography; ZAN, zearalanone; ZEN, zearalenone; $\alpha$-ZAL, $\alpha$-zearalanol; $\alpha$-ZEL, $\alpha$-zearalenol; $\beta$-ZAL, $\beta$-zearalanol; $\beta$-ZEL, $\beta$-zearalenol; $\beta$-ZAL-D $D_{5}, \beta$-zeralanol$10,10,11,12,12-\mathrm{d}_{5} ; 17 \alpha-\mathrm{E}_{2}, 17 \alpha$-estradiol; $17 \beta-\mathrm{E}_{2}, 17 \beta$-estradiol; $17 \beta-\mathrm{E}_{2}-\mathrm{D}_{5}$, $17 \beta$-estradiol-2,4,16,16,17- $\mathrm{d}_{5}$.

Selected paper from the XVI Scientific Meeting of the Spanish Society of Chromatography and Related Techniques (SECyTA 2016), 2-4 November 2016, Seville, Spain.

* Corresponding author.

E-mail addresses: mrguez@ull.edu.es, aqaimpa@ull.es (M.Á. Rodríguez-Delgado).

\section{Introduction}

Natural estrogens are sex steroid hormones that stimulate the development of female characteristics and regulate the menstrual cycle of humans and, in general, the oestrous cycle in mammals. The most important representatives of these natural organismsynthesized compounds, also named as endoestrogens, are estrone $\left(E_{1}\right)$, estradiol $\left(E_{2}\right)$ or estriol $\left(E_{3}\right)$, which have been demonstrated to be present in milk and their derivatives [1].

In addition to the previous group of compounds, there can also be found a wide number of substances called exoestrogens that have an important estrogenic activity (either enhancing or suppressing it). This is the case of ethynylestradiol $\left(\mathrm{EE}_{2}\right)$, a synthetic derivative of $E_{2}$ which is a human contraceptive [2] or synthetic stilbenes such as dienestrol (DS), hexestrol (HEX) or diethylstilbestrol (DES) which are commonly used as growth rate cattle promoters [3]. Another 
important group of exoestrogens is constituted by the so-called mycoestrogens, such as zearalenone (ZEN) and its derivatives zearalanone (ZAN), zearalanols (ZALs) and zearalenols (ZELs), which are, in fact, mycotoxins that can be present in cereal crops and that can be subsequently transferred to milk and, consequently, to their derivatives by animal feeding and also because some of them are used as veterinary drugs [4,5]. Obviously, other exoestrogens or endocrine disruptors such as pesticides, polychlorinated biphenyls, bisphenols, phthalates, etc. are also included in this group.

Apart from these substances, other naturally occurring compounds with estrogenic activity are the so-called phytoestrogens, which are, in fact, isoflavones (i.e. biochanin A, daidzein, formononetin, genistein, glycitein, etc.), lignans (i.e. enterolactone, enterodiol) or coumestans (i.e. coumestrol). Most of them are naturally found in plants whereas others like the lignans enterolactone or enterodiol are obtained as products of animal metabolism. In both cases, and as a result of the vegetable composition of animal feed, they can appear in milk and, consequently, in dairy products $[6,7]$.

Nowadays, there exist several European regulations regarding the use of hormones as animal growth promoters because of their possible toxic effect on public health. In this sense, Directive 2003/74/EC [8], which amends Directive 96/22/EC [9], currently prohibits the specific use of some substances with hormonal activity for the fattening of farm animals to ensure human health protection within the European Union. Among them, $17 \beta-E_{2}$, its ester like derivatives, and stilbenes and their derivatives, as well as their salts and esters, are included. It should be noted that $\alpha-Z A L$, which is also used in several countries for growth promotion, is also banned in Europe. Despite such legislation, there are no specific maximum residue limits (MRLs) established for dairy products for these compounds but the possibility of the widespread abuse of hormonal substances in some parts of Europe still exits.

As a result of the estrogenic activity of all these families of compounds, there is increasing interest in their determination in milk and/or its derivatives, which represents an important group of food commodities widely consumed nowadays by the world population. In fact, several studies have pointed them to be responsible for many disorders of the human reproductive system $[10,11]$ or even cancer [12], though in this last case, and for some of them, there is still controversy in whether they do cause cancer or not $[13,14]$. However, and probably because of the complexity of dairy products, the analysis of these compounds in such products has not been so widely tackled as for other simpler matrices like, for example, water samples $[15,16]$. In fact, only some phyto-, natural and synthetic estrogens have been analyzed in a few occasions in cheese samples (cow cheese) [6,7,17-19], while the analysis of the presence of these groups of compounds in kefir samples has not been reported in the bibliography. In these studies, different extraction techniques were applied including liquid-liquid extraction (LLE) [7,19], LLE combined with solid-phase extraction (SPE) $[16,18]$ and the application of miniaturized techniques as hollowfiber liquid-phase microextraction (HF-LPME) [17].

As it is well known, one of the sample preparation methods most frequently used worldwide, though mainly applied for pesticide residue analysis, is the so-called QuEChERS method [20]. The methodology is highly used in official laboratories that require multiresidue methods in order to maximize sample throughput by minimizing sample preparation, to ensure rapid turnaround time and to carry out effective control. Such approach is very flexible and different versions have been independently developed and applied in monitoring laboratories, mainly in combination with gas chromatography (GC) and liquid chromatography (LC) coupled to mass spectrometry (MS). As a result, the excellent and inherent advantages as well as the results provided by the QuEChERS sample preparation approach combined with both techniques have leaded to its extremely high popularity. In fact, many companies currently sale QuEChERS kits, also adapted to consumers' requirements. Apart from the pesticide residue analysis field, the method has also been successfully applied to the extraction of other groups of compounds like PAHs [21], pharmaceuticals [22], PCBs [23], etc. also from matrices different than fruits or vegetables like mussels [24,25], sewage sludge [22] or fish [25], among others. However, up to now, and to the best of our knowledge, the QuEChERS method has only been used for the extraction of some estrogenic compounds from milk or dairy products such as yogurt in very few occasions [26-29]. However, none of them have determined such compounds in cheese or kefir samples using the QuEChERS method.

Due to the low levels at which these compounds can be found ( $\mu \mathrm{g} / \mathrm{kg}-\mathrm{ng} / \mathrm{kg}$ range), the analysis of estrogenic compounds is frequently performed by chromatographic techniques, being LC coupled to MS via an electrospray ionization (ESI) interface, working in either the positive or, the most common, negative mode [1,11]. The coupling of ultra-high-performance liquid chromatography-tandem MS (UHPLC-MS/MS) using triple quadrupole $(\mathrm{QqQ})$ as analyzer offers relevant advantages in terms of sensitivity as well as specificity which are of great importance for the analysis of complex matrices such as those studied in the present work.

Therefore, this work aims at the evaluation and application of a simple and effective method based on the QuEChERS extraction followed by UHPLC-QqQ-MS/MS determination for the analysis of a wide group of estrogenic compounds constituted by four natural $\left(E_{1}, 17 \alpha-E_{2}, 17 \beta-E_{2}\right.$ and $\left.E_{3}\right)$, four synthetic (DS, DES, HEX and $E_{2}$ ), eight phyto- (daidzein, enterodiol, glycitein, enterolactone, genistein, formononetin, prunetin and biochanin $A$ ) and six mycoestrogens (ZEN, $\alpha$-ZEL, $\beta$-ZEL, ZAN, $\alpha$-ZAL and $\beta$-ZAL) in cheese and kefir of different animal origin. Several real samples were also analyzed. To the best of our knowledge, this is the first time that these compounds are simultaneously extracted from this type of dairy products using the QuEChERS approach. Furthermore, and since certain phytoestrogens were also found in some of the analyzed samples, this manuscript reports the first data available in the literature regarding phytoestrogens content in kefir samples and also constitutes one of the few studies providing data of their occurrence in cheese samples.

\section{Experimental}

\subsection{Chemicals and materials}

Analytical standards of biochanin A (CAS 491-80-5), daidzein (CAS 486-66-8), DES (CAS 56-53-1), DS (CAS 84-17-3), $\mathrm{E}_{1}$ (CAS 53-16-7), $17 \alpha-\mathrm{E}_{2}$ (CAS 57-91-0), 17 $\beta-\mathrm{E}_{2}$ (CAS 50-28-2), 17 $\beta-\mathrm{E}_{2}-$ $\mathrm{D}_{5}$ (CAS 221093-45-4), $\mathrm{E}_{3}$ (CAS 50-27-1), EE 2 (CAS 57-63-6), enterolactone (CAS 78473-71-9), enterodiol (CAS 80226-00-2), formononetin (CAS 485-72-3), genistein (CAS 446-72-0), glycitein (CAS 40957-83-3), HEX (CAS 84-16-2), prunetin (CAS 552-59-0), ZAN (CAS 5975-78-0), $\alpha$-ZAL (CAS 26538-44-3), $\beta$-ZAL (CAS 4242268-4), ZEN (CAS 17924-92-4), $\alpha$-ZEL (CAS 36455-72-8), $\beta$-ZEL (CAS 71030-11-0) from Sigma-Aldrich Chemie (Madrid, Spain) and $\beta$ ZAL-D 5 from Witega Laboratorien Berlin-Adlershof GmbH (Berlin, Germany) were used without further purification (purity $\geq 95 \%$ ).

Stock solutions of each analyte of about $100 \mathrm{mg} / \mathrm{L}$ were precisely prepared in methanol $(\mathrm{MeOH})$ and stored in the darkness at $4{ }^{\circ} \mathrm{C}$. Working analyte mixtures were daily prepared by dilution with the appropriate volume of mobile phase.

All chemicals were of analytical reagent grade (unless otherwise indicated) and used as received. Acetonitrile (ACN) of HPLC grade was from VWR International (Geldenaaksebaan, Belgium), ACN and $\mathrm{MeOH}$ of HPLC-MS hypergrade, were from Merck (Darmstadt, 
Germany), magnesium sulphate monohydrate (97\%) $\left(\mathrm{MgSO}_{4}\right)$, sodium chloride $(\mathrm{NaCl})$ and ammonium hydroxide solution $(\geq 25 \%)$ for trace analysis were from Sigma-Aldrich Chemie (Madrid, Spain) and octadecylsilane $\left(\mathrm{C}_{18}\right)$ sorbent was from Macherey-Nagel (Dürem, Germany). Water was deionized by a Milli-Q gradient system A10 from Millipore (Bedford, MA, USA).

\subsection{Apparatus and software}

UHPLC analyses were performed using a Waters ACQUITY UPLC $\mathrm{H}$-Class (Milford, MA, USA) equipped with a quaternary solvent manager and a sample manager with flow-through needle (FTN) and working with the Masslynx ${ }^{\mathrm{TM}}$ software from Waters Chromatography. The UHPLC system was coupled to a MS Xevo QqQ detector (Waters Chromatography). Control of MS parameters and the collection and process of spectra data were developed using the same software from Waters Chromatography. Separations were carried out at $40^{\circ} \mathrm{C}$ in an Acquity UPLC BEH C $\mathrm{C}_{18}$ column $(50 \mathrm{~mm} \times 2.1 \mathrm{~mm}, 1.7 \mu \mathrm{m})$ using an Acquity UPLC BEH $\mathrm{C}_{18}$ precolumn $(1.7 \mu \mathrm{m})$, both from Waters Chromatography.

The mobile phase used for the analysis of phyto- and mycoestrogens consisted of $\mathrm{MeOH}(\mathrm{A})$ and water (B), while for natural and synthetic estrogens $\mathrm{MeOH} / \mathrm{ACN}$ (50/50, v/v) (A) and $2 \mathrm{mM}$ ammonium hydroxide (B) were used, based on a previous study [29]. The gradient applied was the same for all groups of analytes: $10 \% \mathrm{~A}$ with a flow rate of $0.3 \mathrm{~mL} / \mathrm{min}$ (initial), $10-40 \% \mathrm{~A}$ ( $0.5 \mathrm{~min}$ ), $99.9 \%$ A with an increase of the flow until $0.4 \mathrm{~mL} / \mathrm{min}(7.5 \mathrm{~min}), 99.9 \% \mathrm{~A}$ ( $2 \mathrm{~min}), 10 \% \mathrm{~A}$ with a decrease of the flow to $0.3 \mathrm{~mL} / \mathrm{min}$ (2 min), $10 \% \mathrm{~A}$ ( $2 \mathrm{~min}$ ). The injection volume was $5 \mu \mathrm{L}$ at $10^{\circ} \mathrm{C}$.

The MS system was operated in multiple reaction monitoring (MRM) mode using 1 precursor and 2 product ions [30]. The typical source conditions for maximum intensity of precursor ions were as follows: capillary voltage $2.6 \mathrm{kV}$, source temperature $150^{\circ} \mathrm{C}$, desolvation temperature $150^{\circ} \mathrm{C}$, cone gas $\left(\mathrm{N}_{2}\right)$ flow rate $150 \mathrm{~L} / \mathrm{h}$, desolvation gas $\left(\mathrm{N}_{2}\right)$ flow $550 \mathrm{~L} / \mathrm{h}$, collision gas ( $\mathrm{Ar}$ ) pressure $0.5 \mathrm{bar}$. MS/MS experiments were performed by fragmentation of the deprotonated molecule $[\mathrm{M}-\mathrm{H}]^{-}$or protonated molecule $[\mathrm{M}-\mathrm{H}]^{+}$, depending on each compound, which was selected as the precursor ion. MRM transitions as well as the values of cone voltage and collision energy of the target analytes were automatically optimized by the direct infusion of individual standards of estrogenic compounds at $2 \mathrm{mg} / \mathrm{L}$ in a mixture of $\mathrm{A} / \mathrm{B}(50: 50, \mathrm{v} / \mathrm{v})$ for each group of compounds. Optimized MRM transitions as well as the values of cone voltage and collision energy of the target analytes are listed in Table S1 of the Supplementary material.

\subsection{Samples selection}

Four different dairy products, including two types of white cow cheese samples (skimmed and whole) and two kinds of kefir with goat and cow origin, were selected in order to validate the methodology. All samples were bought in local supermarkets of Tenerife (Canary Islands, Spain). The content of proteins, carbohydrates and fats were in the ranges $3.1-12 \mathrm{~g}, 3.5-4.4 \mathrm{~g}$ and $0.2-10 \mathrm{~g}$ per $100 \mathrm{~g}$ of sample, respectively, which is indicated on the commercial packaging of each product.

\subsection{Dairy products extraction}

The QuEChERS method [31] was applied for the extraction of the 22 estrogenic compounds from the selected dairy product samples. All products were previously homogenized using a T10 basic Ultra-Turrax from IKA (Staufen, Germany) for $3 \mathrm{~min}$ at a speed of approximately 11500 r.p.m. Then, $10 \mathrm{~g}$ of each sample were weighed into a $50 \mathrm{~mL}$ polypropylene (PP) centrifuge tube and $5 \mathrm{~mL}$ of Milli-Q water were added and mixed by shaking for $1 \mathrm{~min}$. After that, $15 \mathrm{~mL}$ of ACN were added and the mixture was again shaken for $1 \mathrm{~min}$, followed by the addition of $6 \mathrm{~g}$ of $\mathrm{MgSO}_{4}$ and $1.5 \mathrm{~g}$ of $\mathrm{NaCl}$, shaking during $1 \mathrm{~min}$, ultrasounds for $5 \mathrm{~min}$ and centrifugation at 4400 r.p.m. for $15 \mathrm{~min}$ in a 5702 centrifuge from Eppendorf (Hamburg, Germany). The supernatant was transferred to a new $\mathrm{PP}$ centrifuge tube of $50 \mathrm{~mL}$ containing $180 \mathrm{mg}$ of $\mathrm{C}_{18}$ sorbent and $1.8 \mathrm{~g}$ of $\mathrm{MgSO}_{4}$, shaken for $1 \mathrm{~min}$ and centrifuged in the same conditions as in the first part of the procedure. Afterwards, $8 \mathrm{~mL}$ of the supernatant were collected and evaporated at $40^{\circ} \mathrm{C}$ and $180 \mathrm{mbar}$ using a Rotavapor R-200 equipped with a V-800 vacuum controller, and a V-500 vacuum pump, all of them from Büchi Labortechnik. Finally, the residue was reconstituted in $500 \mu \mathrm{L}$ of $50 / 50 \mathrm{v} / \mathrm{v}$ $\mathrm{MeOH} /$ water and filtered using a Chromafil ${ }^{\circledR}$ Xtra PET-20/15 filter from Macherey-Nagel. In the case of whole cheese, a higher amount of $\mathrm{C}_{18}$ (500 mg) was necessary to remove the fat of the matrix during the clean-up step.

\section{Results and discussion}

\subsection{UHPLC-MS/MS method}

In order to proceed with the LC separation of the analytes, UHPLC-MS/MS conditions described in Section 2.2 were used. Results were found satisfactory with a very good separation of all the analytes and an analysis time of $5 \mathrm{~min}$, using two different mobile phase compositions, one for the group of natural and synthetic estrogens and another for the combination of myco-and phytoestrogens. A repeatability study consisting on six consecutive injections $(n=6)$ of a mixture of the analytes at three levels of concentration $(5,250$ and $500 \mu \mathrm{g} / \mathrm{L})$ in three different days $(\mathrm{n}=18)$ was carried out. Good repeatability for the retention times and peak areas were observed for all concentration levels in the same day, with RSDs lower than $0.4 \%$ and $14 \%$, and between days, with RSD below $0.5 \%$ and $16 \%$, respectively. Afterwards, instrumental calibration curves based on the relation of each analyte and the internal standard (IS) peak areas were obtained for each estrogenic compound by injecting seven concentration levels in quadruplicate $(n=7)$, obtaining determination coefficients $\left(R^{2}\right)$ higher than 0.9968 , as can be seen in Table 1 . The ISs used were $\beta-Z A L-D_{5}$ for myco- and phytoestrogens and $17 \beta-\mathrm{E}_{2}-\mathrm{D}_{5}$ for natural and synthetic estrogens, which have a similar structure and behaviour to the group of the target analytes for which were applied. They were selected in order to correct the possible errors during sample preparation and to improve its reproducibility [32,33].

\subsection{QuEChERS-UHPLC-MS/MS method validation}

Dairy products are very complex samples with particular characteristics that can modify considerably the results obtained when the methodology is applied, especially in terms of accuracy and precision. For this reason, the study of the effect that such matrices can produce in the application of the developed methodology is of great interest. With this aim, matrix effect was evaluated in all cases following the Matuszewski method [34]. For this purpose, five replicates of each matrix were extracted by the QuEChERS method once spiked at three different concentration levels (low level: $1.88 \mu \mathrm{g} / \mathrm{kg}$, except in cow kefir where they were $4 \mu \mathrm{g} / \mathrm{kg}$ for ZAN and $2.56 \mu \mathrm{g} / \mathrm{kg}$ for natural and synthetic estrogens and formononetin and prunetin; medium level: $17.5 \mu \mathrm{g} / \mathrm{kg}$ and high level: $37.5 \mu \mathrm{g} / \mathrm{kg}$ ) at the end of the process and analyzed by UHPLC-QqQMS/MS. Then, matrix effect was calculated as the percentage of the ratio of the spiked sample and the standard area at the same concentration as proposed by Matuszewski et al. [34]. As can be seen in Table 2, the values of the percentage of matrix effect vary considerably between matrices and analytes, finding percentages lower 
Table 1

Instrumental calibration data of the selected compounds.

\begin{tabular}{|c|c|c|c|c|c|}
\hline \multirow[t]{2}{*}{ Analyte } & \multirow[t]{2}{*}{ Retention time (min) } & \multicolumn{4}{|c|}{ Calibration data $(\mathrm{n}=7)$} \\
\hline & & Range of concentration studied( $\mu \mathrm{g} / \mathrm{L})$ & Slope & Intercept & $\mathrm{R}^{2}$ \\
\hline \multicolumn{6}{|c|}{ Phytoestrogens } \\
\hline Daidzein & 3.01 & $0.50-750$ & $8.06 \cdot 10^{-4} \pm 2.67 \cdot 10^{-5}$ & $1.62 \cdot 10^{-3} \pm 7.85 \cdot 10^{-3}$ & 0.9992 \\
\hline Enterodiol & 3.09 & $0.50-750$ & $4.05 \cdot 10^{-4} \pm 2.64 \cdot 10^{-5}$ & $4.81 \cdot 10^{-3} \pm 9.53 \cdot 10^{-3}$ & 0.9970 \\
\hline Glycitein & 3.12 & $0.50-750$ & $1.06 \cdot 10^{-3} \pm 6.60 \cdot 10^{-5}$ & $6.79 \cdot 10^{-3} \pm 2.06 \cdot 10^{-2}$ & 0.9971 \\
\hline Enterolactone & 3.29 & $0.50-750$ & $1.21 \cdot 10^{-3} \pm 2.57 \cdot 10^{-5}$ & $3.72 \cdot 10^{-3} \pm 9.28 \cdot 10^{-3}$ & 0.9997 \\
\hline Genistein & 3.39 & $0.50-750$ & $1.56 \cdot 10^{-3} \pm 5.10 \cdot 10^{-5}$ & $8.37 \cdot 10^{-3} \pm 1.79 \cdot 10^{-2}$ & 0.9992 \\
\hline Formononetin & 4.09 & $1.0-750$ & $5.32 \cdot 10^{-1} \pm 1.04 \cdot 10^{-5}$ & $-3.80 \cdot 10^{-3} \pm 3.64 \cdot 10^{-3}$ & 0.9997 \\
\hline Prunetin & 4.57 & $1.0-750$ & $1.61 \cdot 10^{-1} \pm 1.83 \cdot 10^{-4}$ & $2.63 \cdot 10^{-2} \pm 6.60 \cdot 10^{-2}$ & 0.9999 \\
\hline Biochanin A & 4.66 & $0.50-750$ & $2.57 \cdot 10^{-2} \pm 9.14 \cdot 10^{-4}$ & $5.80 \cdot 10^{-2} \pm 3.29 \cdot 10^{-1}$ & 0.9991 \\
\hline \multicolumn{6}{|c|}{ Mycoestrogens } \\
\hline$\beta-\mathrm{ZAL}$ & 3.99 & $0.50-750$ & $2.17 \cdot 10^{-3} \pm 2.34 \cdot 10^{-5}$ & $2.62 \cdot 10^{-3} \pm 8.44 \cdot 10^{-3}$ & 0.9999 \\
\hline$\beta-Z E L$ & 4.16 & $0.50-750$ & $1.04 \cdot 10^{-3} \pm 4.29 \cdot 10^{-5}$ & $7.06 \cdot 10^{-3} \pm 1.47 \cdot 10^{-2}$ & 0.9980 \\
\hline$\alpha-\mathrm{ZAL}$ & 4.51 & $0.50-750$ & $6.42 \cdot 10^{-3} \pm 1.45 \cdot 10^{-4}$ & $3.22 \cdot 10^{-2} \pm 5.05 \cdot 10^{-2}$ & 0.9996 \\
\hline$\alpha-Z E L$ & 4.64 & $0.50-750$ & $8.90 \cdot 10^{-4} \pm 4.32 \cdot 10^{-5}$ & $1.01 \cdot 10^{-2} \pm 1.48 \cdot 10^{-2}$ & 0.9980 \\
\hline ZAN & 4.72 & $0.50-750$ & $4.40 \cdot 10^{-2} \pm 1.96 \cdot 10^{-3}$ & $6.23 \cdot 10^{-1} \pm 6.69 \cdot 10^{-1}$ & 0.9980 \\
\hline ZEN & 4.82 & $0.50-750$ & $3.84 \cdot 10^{-3} \pm 5.30 \cdot 10^{-5}$ & $1.37 \cdot 10^{-3} \pm 1.92 \cdot 10^{-2}$ & 0.9999 \\
\hline \multicolumn{6}{|c|}{ Synthetic estrogens } \\
\hline $\mathrm{EE}_{2}$ & 3.88 & $5.0-750$ & $1.58 \cdot 10^{-3} \pm 5.18 \cdot 10^{-5}$ & $-1.49 \cdot 10^{-2} \pm 1.87 \cdot 10^{-2}$ & 0.9990 \\
\hline DES & 4.13 & $5.0-750$ & $8.61 \cdot 10^{-3} \pm 5.00 \cdot 10^{-4}$ & $3.67 \cdot 10^{-2} \pm 1.75 \cdot 10^{-1}$ & 0.9975 \\
\hline DS & 4.34 & $5.0-750$ & $1.35 \cdot 10^{-2} \pm 1.56 \cdot 10^{-4}$ & $-4.87 \cdot 10^{-2} \pm 4.62 \cdot 10^{-2}$ & 0.9999 \\
\hline HEX & 4.34 & $5.0-750$ & $1.83 \cdot 10^{-2} \pm 1.03 \cdot 10^{-3}$ & $-2.61 \cdot 10^{-2} \pm 3.60 \cdot 10^{-1}$ & 0.9976 \\
\hline \multicolumn{6}{|c|}{ Natural estrogens } \\
\hline $\mathrm{E}_{3}$ & 2.43 & $5.0-750$ & $1.88 \cdot 10^{-3} \pm 8.11 \cdot 10^{-5}$ & $-5.80 \cdot 10^{-3} \pm 2.98 \cdot 10^{-2}$ & 0.9983 \\
\hline $17 \beta-E_{2}$ & 3.68 & $5.0-750$ & $1.53 \cdot 10^{-3} \pm 9.84 \cdot 10^{-5}$ & $-3.46 \cdot 10^{-3} \pm 3.10 \cdot 10^{-2}$ & 0.9968 \\
\hline $17 \alpha-E_{2}$ & 3.88 & $5.0-750$ & $1.99 \cdot 10^{-3} \pm 8.83 \cdot 10^{-5}$ & $-3.34 \cdot 10^{-2} \pm 3.10 \cdot 10^{-2}$ & 0.9982 \\
\hline $\mathrm{E}_{1}$ & 3.92 & $5.0-750$ & $1.02 \cdot 10^{-2} \pm 2.10 \cdot 10^{-4}$ & $-5.11 \cdot 10^{-2} \pm 6.21 \cdot 10^{-2}$ & 0.9997 \\
\hline
\end{tabular}

$\mathrm{R}^{2}$ : Determination coefficient.

than $80 \%$ for the majority of cases with RSD lower than $19 \%$, except for DES, DS, HEX, $17 \beta-E_{2}$ and $E_{1}$ in goat kefir, $E_{3}$ in cow kefir and enterodiol in whole cheese for which the matrix effect percentage was higher than $80 \%$. These results indicated a clear ion suppression effect of the matrices for almost all cases and, consequently, it brought about the necessity of taking such aspect into account for the rest of the study.

The QuEChERS-UHPLC-MS/MS method was then applied and validated for the analysis of whole and skimmed cow cheese as well as kefir with cow and goat origin. For this purpose, calibration curves were prepared in order to evaluate the linearity of the methodology in the range of concentration of interest. Due to the results obtained from the matrix effect study, matrix-matched calibration curves were developed in each case. With this aim the samples where spiked at the end of the process and the curves were prepared based on the ratio between analyte and IS peak areas chosen for each group of analytes, by injecting 7 different levels of concentrations in quadruplicate $(n=7)$. Results, including the studied linear range with the lowest calibration level, are shown in Table 3. As can be seen, determination coefficients $\left(\mathrm{R}^{2}\right)$ obtained in all cases were higher than 0.9905. LOQs of the method, defined as the lowest matrix matched calibration concentration which provided a signal to noise ratio higher than 10 for the quantification transition and at least 3 for the confirmation transition (if it was available) were in the range $0.025-0.250 \mu \mathrm{g} / \mathrm{kg}$ for skimmed cheese, $0.050-0.500 \mu \mathrm{g} / \mathrm{kg}$ for whole cheese and in the ranges $0.050-2.50 \mu \mathrm{g} / \mathrm{kg}$ and $0.050-0.500 \mu \mathrm{g} / \mathrm{kg}$ for cow and goat kefir, respectively.

With the aim of studying the reproducibility of the procedure, recovery studies were developed for all samples at three levels of concentration carrying out 5 replicates at each level (see Table 4).
A blank matrix of each type was also extracted and spiked at the same concentration level at the end of the extraction procedure. No interferences were found in any of them when blanks of the matrices were evaluated. Fig. 1 shows the quantification transition obtained for each analyte when cow kefir was analyzed. Similar chromatograms were also obtained for the other three types of dairy products. However, the presence of some of the target analytes could be determined when the blank matrices were analyzed. As can be seen in Fig. 2 for the whole cheese matrix, daidzein, glycitein, enterolactone and genistein were detected in some of the studied matrices. Consequently, and in order to carry out the correct validation of the procedure for all analytes, their areas were subtracted during the study. Relative recovery values were calculated taking into account the matrix effect, that is to say, comparing samples spiked at the beginning and at the end of the methodology. The obtained results, which are shown in Table 4, demonstrated the excellent reproducibility as well as the good efficiency of the extraction procedure applied in this case, since relative recovery values were in the range $78-119 \%, 70-119 \%, 73-119 \%, 71-118 \%$ for skimmed and whole cheese and cow and goat kefir, respectively, with RSD values lower than $14 \%$ for all samples.

\subsection{Analysis of real samples}

Once the methodology was validated and taking into account the excellent results obtained, a group of 8 real samples from diverse commercial brands, purchased in different supermarkets of Tenerife, were analyzed using the developed QuEChERS-UHPLCQqQ-MS/MS method. This group included 2 different samples of each type of matrix studied. Their content of carbohydrates, proteins and fats are shown in Table S2 of the Supplementary material. 
$\mathbf{a}$
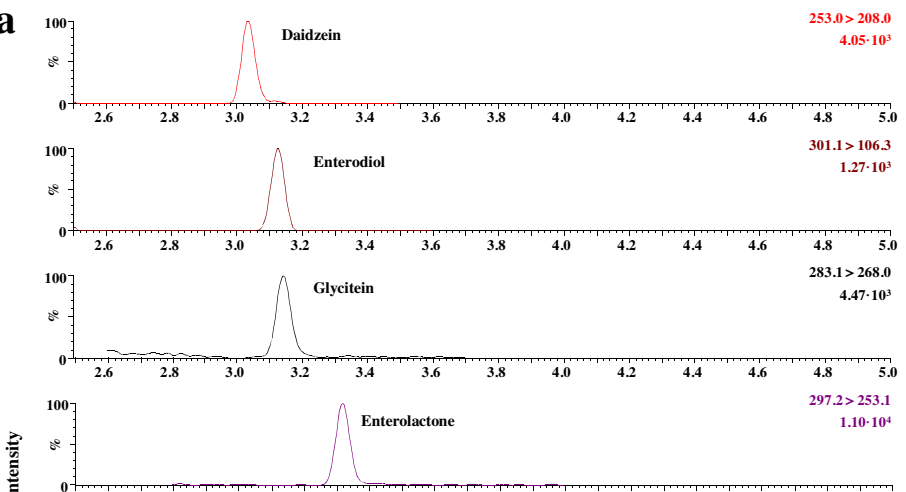

苋
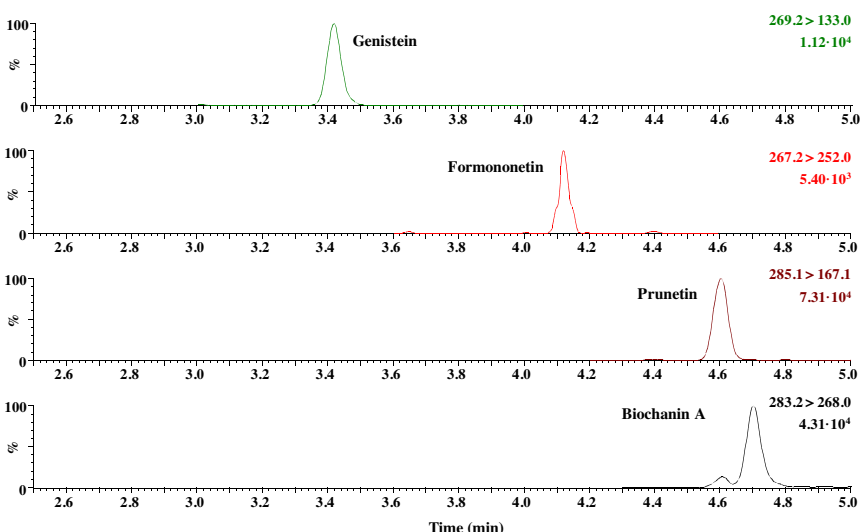
Time (min)

b
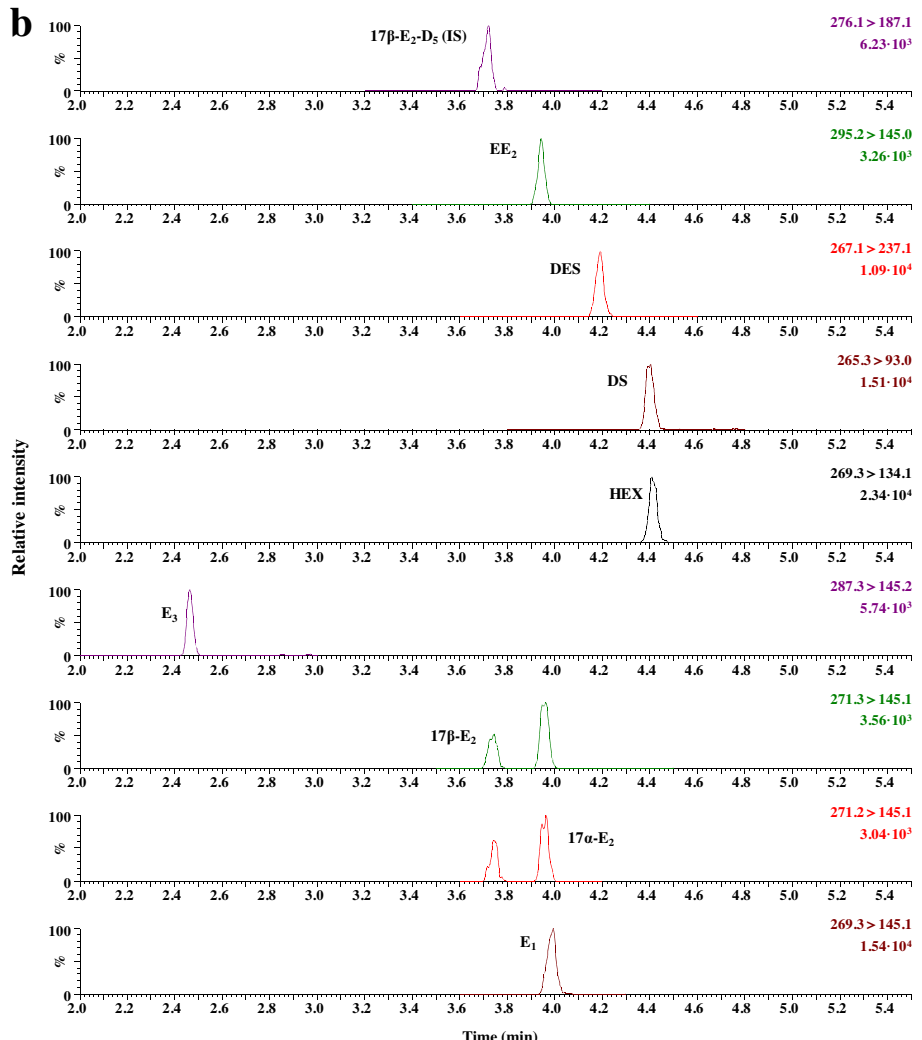
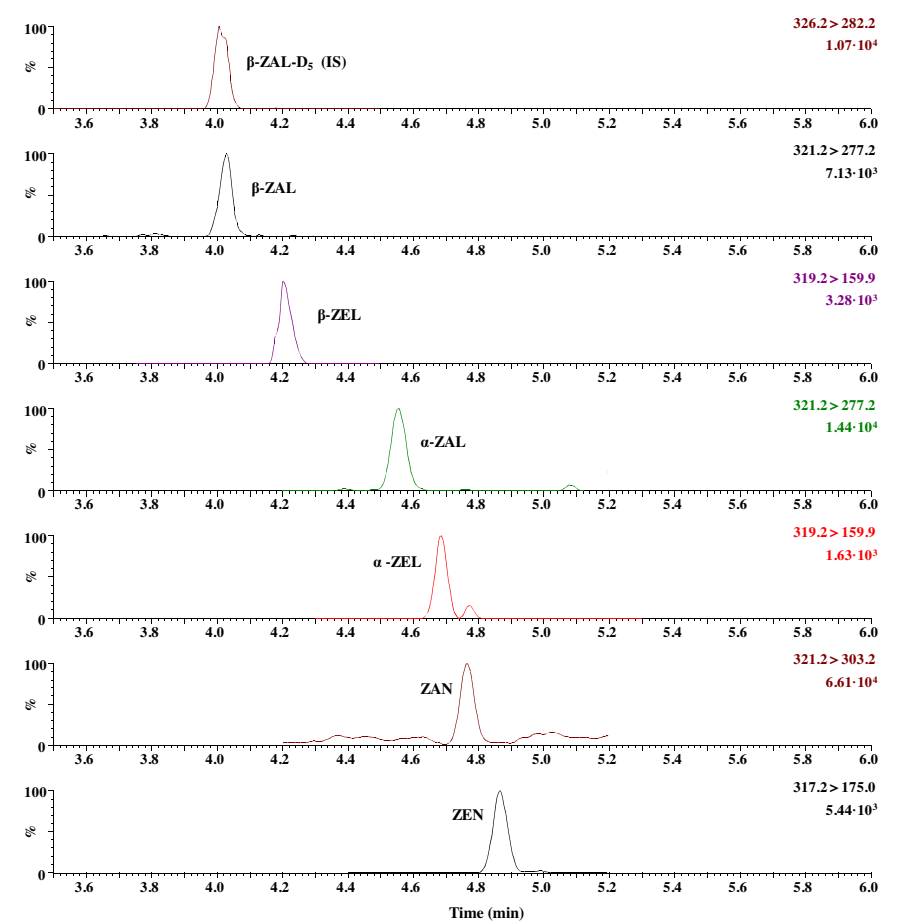

$$
7.1
$$


Table 2

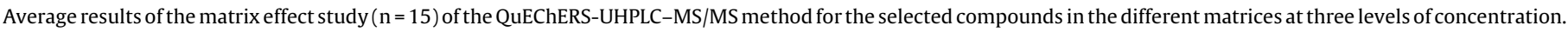

\begin{tabular}{|c|c|c|c|c|c|c|c|}
\hline Analyte & Type of matrix & $M E^{a, b} \%$ & $\mathrm{RSD}, \%$ & Analyte & Type of matrix & $M E^{a, b} \%$ & RSD, \% \\
\hline \multirow[t]{4}{*}{ Daidzein } & Skimmed cheese & 62 & 4 & $\alpha$-ZEL & Skimmed cheese & 30 & 17 \\
\hline & Whole cheese & 49 & 17 & & Whole cheese & 28 & 8 \\
\hline & Cow kefir & 33 & 11 & & Cow kefir & 29 & 12 \\
\hline & Goat kefir & 20 & 8 & & Goat kefir & 19 & 5 \\
\hline \multirow[t]{4}{*}{ Enterodiol } & Skimmed cheese & 70 & 11 & ZAN & Skimmed cheese & 63 & 19 \\
\hline & Whole cheese & 82 & 5 & & Whole cheese & 26 & 19 \\
\hline & Cow kefir & 33 & 2 & & Cow kefir & 33 & 18 \\
\hline & Goat kefir & 18 & 4 & & Goat kefir & 16 & 5 \\
\hline \multirow[t]{4}{*}{ Glycitein } & Skimmed cheese & 54 & 9 & ZEN & Skimmed cheese & 25 & 9 \\
\hline & Whole cheese & 66 & 17 & & Whole cheese & 14 & 18 \\
\hline & Cow kefir & 43 & 12 & & Cow kefir & 20 & 9 \\
\hline & Goat kefir & 18 & 14 & & Goat kefir & 16 & 7 \\
\hline \multirow[t]{4}{*}{ Enterolactone } & Skimmed cheese & 19 & 6 & $\mathrm{EE}_{2}$ & Skimmed cheese & 60 & 8 \\
\hline & Whole cheese & 33 & 10 & & Whole cheese & 43 & 1 \\
\hline & Cow kefir & 45 & 8 & & Cow kefir & 67 & 5 \\
\hline & Goat kefir & 28 & 18 & & Goat kefir & 77 & 18 \\
\hline \multirow[t]{4}{*}{ Genistein } & Skimmed cheese & 51 & 15 & DES & Skimmed cheese & 48 & 5 \\
\hline & Whole cheese & 58 & 8 & & Whole cheese & 31 & 6 \\
\hline & Cow kefir & 39 & 7 & & Cow kefir & 61 & 15 \\
\hline & Goat kefir & 21 & 6 & & Goat kefir & 92 & 4 \\
\hline \multirow[t]{4}{*}{ Formononetin } & Skimmed cheese & 39 & 19 & DS & Skimmed cheese & 52 & 3 \\
\hline & Whole cheese & 39 & 6 & & Whole cheese & 34 & 4 \\
\hline & Cow kefir & 34 & 18 & & Cow kefir & 65 & 5 \\
\hline & Goat kefir & 24 & 4 & & Goat kefir & 87 & 3 \\
\hline \multirow[t]{4}{*}{ Prunetin } & Skimmed cheese & 54 & 18 & HEX & Skimmed cheese & 48 & 3 \\
\hline & Whole cheese & 27 & 17 & & Whole cheese & 30 & 6 \\
\hline & Cow kefir & 34 & 17 & & Cow kefir & 65 & 4 \\
\hline & Goat kefir & 37 & 11 & & Goat kefir & 82 & 4 \\
\hline \multirow[t]{4}{*}{ Biochanin A } & Skimmed cheese & 23 & 5 & $\mathrm{E}_{3}$ & Skimmed cheese & 56 & 11 \\
\hline & Whole cheese & 14 & 4 & & Whole cheese & 72 & 8 \\
\hline & Cow kefir & 23 & 8 & & Cow kefir & 90 & 5 \\
\hline & Goat kefir & 22 & 9 & & Goat kefir & 78 & 14 \\
\hline \multirow[t]{4}{*}{$\beta-Z A L$} & Skimmed cheese & 42 & 16 & $17 \beta-\mathrm{E}_{2}$ & Skimmed cheese & 47 & 3 \\
\hline & Whole cheese & 43 & 9 & & Whole cheese & 43 & 4 \\
\hline & Cow kefir & 32 & 17 & & Cow kefir & 72 & 3 \\
\hline & Goat kefir & 14 & 13 & & Goat kefir & 87 & 18 \\
\hline \multirow[t]{4}{*}{$\beta-Z E L$} & Skimmed cheese & 46 & 10 & $17 \alpha-\mathrm{E}_{2}$ & Skimmed cheese & 60 & 5 \\
\hline & Whole cheese & 39 & 17 & & Whole cheese & 42 & 3 \\
\hline & Cow kefir & 24 & 6 & & Cow kefir & 70 & 4 \\
\hline & Goat kefir & 17 & 11 & & Goat kefir & 80 & 9 \\
\hline \multirow[t]{4}{*}{$\alpha-Z A L$} & Skimmed cheese & 26 & 16 & $\mathrm{E}_{1}$ & Skimmed cheese & 62 & 7 \\
\hline & Whole cheese & 28 & 3 & & Whole cheese & 44 & 17 \\
\hline & Cow kefir & 31 & 4 & & Cow kefir & 67 & 8 \\
\hline & Goat kefir & 21 & 17 & & Goat kefir & 87 & 6 \\
\hline
\end{tabular}

a Results obtained as an average of each analyte at the same concentration level of the recovery studies.

b Calculated following the Matuszewski method [34].

Results, which are presented in Table 5, show the presence of some phytoestrogens (daidzein, glycitein, enterolactone and genistein) in the analyzed samples. Besides, some of them could be even quantified since they are present at concentrations above the LOQ of the method (in the range $1.14-46.7 \mu \mathrm{g} / \mathrm{kg}$ ), while the presence of mycoestrogens, natural or synthetic estrogens was not observed in any of the samples.

As indicated in the introduction section, the content of phytoestrogens in kefir samples has not been reported up to now since these compounds have not been previously analyzed in such matrices. Regarding cheese samples, the obtained results, in the range of $1.76-46.7 \mu \mathrm{g} / \mathrm{kg}$ for daidzein, glycitein and enterolactone, are comparable to the content previously determined by Křižová et al. [7] who reported values around $11.7-30.5 \mu \mathrm{g} / \mathrm{kg}$ for daidzein, genistein and glycitein, and slightly lower that the data reported by Kuhnle et al. [6] who found enterolactone in concentrations of $30-230 \mu \mathrm{g} / \mathrm{kg}$ in different type of cheese products. As it was demonstrated by Křižová et al. [7], these differences can be associated with the animal diet as well as the type of process applied to each product which can modify considerably the initial level of phytoestrogens present in the raw material used for its preparation.

These results demonstrate the suitability of the methodology for the analysis of the target compounds as well as the importance of their development for the evaluation of the presence of such compounds in samples extensively consumed by the population like milk derivatives.

\subsection{Comparison with other methodologies}

As it was indicated in the introduction section, only a few studies have been published regarding the evaluation of estrogenic compounds in milk or milk derivatives [6,7,17-19,26-29] except for kefir samples, which has not been previously analyzed. Concerning cheese samples, it should be indicated that it has only been previously analyzed to determine phyto-, natural and synthetic estrogens, but not mycoestrogens $[6,7,17,18]$. In this sense, Guoliang et al. applied a simple solvent extraction procedure followed by HPLC-FD with a previous derivatization with ethyl-acridinesulfonyl chloride for the determination of $E_{1}, E_{2}$ and $E_{3}$ among other type of compounds. However, no data related with the sensitivity of the methodology were indicated for this specific matrix. A similar approach was carried out by Chavaliere et al. [18] who applied an ultrasound assisted solvent extraction using $1 \mathrm{~g}$ of cheese sample and a mixture of $5 \mathrm{~mL}$ of $\mathrm{MeOH} /$ water $(80: 20, \mathrm{v} / \mathrm{v})$ containing $1 \%(v / v)$ trifluoroacetic acid as extraction solvent, followed by a SPE clean-up step using graphitized carbon black, for the extraction of 
Matrix matched calibration data of the selected compounds in the different matrices.

\begin{tabular}{|c|c|c|c|c|c|c|c|c|c|c|c|}
\hline \multirow[t]{2}{*}{ Analyte } & \multirow[t]{2}{*}{ Type of matrix } & \multicolumn{4}{|c|}{ Calibration data $(\mathrm{n}=7)$} & \multirow[t]{2}{*}{ Analyte } & \multirow[t]{2}{*}{ Type of matrix } & \multicolumn{4}{|c|}{ Calibration data $(\mathrm{n}=7)$} \\
\hline & & $\begin{array}{l}\text { Range of } \\
\text { concentratio } \\
\text { studied } \\
(\mu \mathrm{g} / \mathrm{L})\end{array}$ & $\begin{array}{l}\text { Slope } \\
\text { on }\end{array}$ & Intercept & $\mathrm{R}^{2}$ & & & $\begin{array}{l}\text { Range of } \\
\text { concentratio } \\
\text { studied } \\
(\mu \mathrm{g} / \mathrm{L})\end{array}$ & $\begin{array}{l}\text { Slope } \\
\text { on }\end{array}$ & Intercept & $\mathrm{R}^{2}$ \\
\hline \multirow[t]{4}{*}{ Daidzein } & Skimmed cheese & $0.5-750$ & $1.43 \cdot 10^{-3} \pm 6.53 \cdot 10^{-5}$ & $-9.08 \cdot 10^{-3} \pm 2.01 \cdot 10^{-2}$ & 0.9984 & $\alpha$-ZEL & Skimmed cheese & $5-750$ & $8.29 \cdot 10^{-4} \pm 4.08 \cdot 10^{-5}$ & $-1.73 \cdot 10^{-3} \pm 1.26 \cdot 10^{-2}$ & 0.9982 \\
\hline & Whole cheese & $1-750$ & $1.54 \cdot 10^{-3} \pm 3.57 \cdot 10^{-5}$ & $3.17 \cdot 10^{-4} \pm 1.10 \cdot 10^{-2}$ & 0.9996 & & Whole cheese & $5-750$ & $5.70 \cdot 10^{-4} \pm 2.46 \cdot 10^{-5}$ & $-1.98 \cdot 10^{-3} \pm 7.80 \cdot 10^{-3}$ & 0.9986 \\
\hline & Cow kefir & $1-750$ & $1.67 \cdot 10^{-3} \pm 1.47 \cdot 10^{-4}$ & $1.71 \cdot 10^{-2} \pm 4.54 \cdot 10^{-2}$ & 0.9942 & & Cow kefir & $5-750$ & $6.44 \cdot 10^{-4} \pm 1.99 \cdot 10^{-5}$ & $-7.15 \cdot 10^{-3} \pm 7.20 \cdot 10^{-3}$ & 0.9993 \\
\hline & Goat kefir & $1-750$ & $1.31 \cdot 10^{-3} \pm 8.49 \cdot 10^{-5}$ & $1.46 \cdot 10^{-2} \pm 2.91 \cdot 10^{-2}$ & 0.9968 & & Goat kefir & $10-750$ & $6.39 \cdot 10^{-4} \pm 3.66 \cdot 10^{-5}$ & $3.08 \cdot 10^{-3} \pm 1.09 \cdot 10^{-2}$ & 0.9975 \\
\hline \multirow[t]{4}{*}{ Enterodiol } & Skimmed cheese & $5-750$ & $1.07 \cdot 10^{-3} \pm 7.59 \cdot 10^{-5}$ & $-1.60 \cdot 10^{-2} \pm 2.74 \cdot 10^{-2}$ & 0.9962 & ZAN & Skimmed cheese & $5-750$ & $4.91 \cdot 10^{-2} \pm 4.16 \cdot 10^{-3}$ & $-5.65 \cdot 10^{-1} \pm 1.28 \cdot 10$ & 0.9946 \\
\hline & Whole cheese & $5-750$ & $1.09 \cdot 10^{-3} \pm 9.47 \cdot 10^{-6}$ & $6.08 \cdot 10^{-4} \pm 2.80 \cdot 10^{-3}$ & 0.9999 & & Whole cheese & $5-750$ & $1.51 \cdot 10^{-2} \pm 4.03 \cdot 10^{-4}$ & $7.51 \cdot 10^{-2} \pm 1.28 \cdot 10^{-1}$ & 0.9995 \\
\hline & Cow kefir & $10-750$ & $1.18 \cdot 10^{-3} \pm 3.92 \cdot 10^{-5}$ & $-4.26 \cdot 10^{-3} \pm 1.25 \cdot 10^{-2}$ & 0.9992 & & Cow kefir & $50-750$ & $8.69 \cdot 10^{-3} \pm 1.18 \cdot 10^{-3}$ & $7.52 \cdot 10^{-1} \pm 4.70 \cdot 10^{-1}$ & 0.9905 \\
\hline & Goat kefir & $5-750$ & $6.81 \cdot 10^{-4} \pm 3.72 \cdot 10^{-5}$ & $-7.64 \cdot 10^{-3} \pm 1.34 \cdot 10^{-2}$ & 0.9977 & & Goat kefir & $5-750$ & $6.20 \cdot 10^{-2} \pm 2.27 \cdot 10^{-3}$ & $5.97 \cdot 10^{-2} \pm 7.75 \cdot 10^{-1}$ & 0.9990 \\
\hline \multirow[t]{4}{*}{ Glycitein } & Skimmed cheese & $1-750$ & $2.26 \cdot 10^{-3} \pm 5.50 \cdot 10^{-5}$ & $8.28 \cdot 10^{-3} \pm 1.69 \cdot 10^{-2}$ & 0.9995 & ZEN & Skimmed cheese & $1-750$ & $6.53 \cdot 10^{-3} \pm 7.04 \cdot 10^{-4}$ & $-9.70 \cdot 10^{-2} \pm 2.16 \cdot 10^{-1}$ & 0.9913 \\
\hline & Whole cheese & $5-750$ & $2.34 \cdot 10^{-3} \pm 9.40 \cdot 10^{-5}$ & $2.22 \cdot 10^{-2} \pm 2.98 \cdot 10^{-2}$ & 0.9988 & & Whole cheese & $5-750$ & $1.90 \cdot 10^{-3} \pm 8.65 \cdot 10^{-5}$ & $-1.75 \cdot 10^{-2} \pm 2.64 \cdot 10^{-2}$ & 0.9984 \\
\hline & Cow kefir & $10-750$ & $2.39 \cdot 10^{-3} \pm 1.47 \cdot 10^{-4}$ & $4.06 \cdot 10^{-2} \pm 5.31 \cdot 10^{-2}$ & 0.9971 & & Cow kefir & $5-750$ & $2.73 \cdot 10^{-3} \pm 1.34 \cdot 10^{-4}$ & $-3.59 \cdot 10^{-2} \pm 4.69 \cdot 10^{-2}$ & 0.9982 \\
\hline & Goat kefir & $10-750$ & $2.90 \cdot 10^{-3} \pm 2.03 \cdot 10^{-4}$ & $2.53 \cdot 10^{-2} \pm 7.35 \cdot 10^{-2}$ & 0.9963 & & Goat kefir & $5-750$ & $4.67 \cdot 10^{-3} \pm 1.40 \cdot 10^{-4}$ & $-2.39 \cdot 10^{-2} \pm 4.80 \cdot 10^{-2}$ & 0.9993 \\
\hline \multirow[t]{4}{*}{ Enterolactone } & Skimmed cheese & $1-750$ & $3.30 \cdot 10^{-3} \pm 1.28 \cdot 10^{-4}$ & $8.75 \cdot 10^{-2} \pm 3.93 \cdot 10^{-2}$ & 0.9988 & $\mathrm{EE}_{2}$ & Skimmed cheese & $5-750$ & $3.39 \cdot 10^{-3} \pm 4.78 \cdot 10^{-5}$ & $-2.38 \cdot 10^{-2} \pm 1.47 \cdot 10^{-2}$ & 0.9997 \\
\hline & Whole cheese & $5-750$ & $2.70 \cdot 10^{-3} \pm 1.50 \cdot 10^{-4}$ & $6.78 \cdot 10^{-2} \pm 5.52 \cdot 10^{-2}$ & 0.9971 & & Whole cheese & $5-750$ & $1.42 \cdot 10^{-3} \pm 1.16 \cdot 10^{-4}$ & $-3.11 \cdot 10^{-2} \pm 3.42 \cdot 10^{-2}$ & 0.9950 \\
\hline & Cow kefir & $5-750$ & $8.83 \cdot 10^{-3} \pm 8.29 \cdot 10^{-5}$ & $3.25 \cdot 10^{-2} \pm 2.90 \cdot 10^{-2}$ & 0.9999 & & Cow kefir & $10-750$ & $2.06 \cdot 10^{-3} \pm 2.10 \cdot 10^{-4}$ & $-6.47 \cdot 10^{-2} \pm 6.24 \cdot 10^{-2}$ & 0.9922 \\
\hline & Goat kefir & $5-750$ & $3.98 \cdot 10^{-3} \pm 2.43 \cdot 10^{-4}$ & $8.33 \cdot 10^{-2} \pm 7.22 \cdot 10^{-2}$ & 0.9972 & & Goat kefir & $5-750$ & $2.07 \cdot 10^{-3} \pm 9.61 \cdot 10^{-5}$ & $-3.18 \cdot 10^{-2} \pm 2.96 \cdot 10^{-2}$ & 0.9984 \\
\hline \multirow{4}{*}{ Genistein } & Skimmed cheese & $1-750$ & $2.97 \cdot 10^{-3} \pm 3.26 \cdot 10^{-4}$ & $-1.99 \cdot 10^{-2} \pm 1.14 \cdot 10^{-1}$ & 0.9910 & DES & Skimmed cheese & $5-750$ & $1.24 \cdot 10^{-2} \pm 7.25 \cdot 10^{-4}$ & $-8.96 \cdot 10^{-2} \pm 2.29 \cdot 10^{-1}$ & 0.9974 \\
\hline & Whole cheese & $5-750$ & $2.23 \cdot 10^{-3} \pm 1.11 \cdot 10^{-4}$ & $-1.65 \cdot 10^{-2} \pm 3.29 \cdot 10^{-2}$ & 0.9981 & & Whole cheese & $5-750$ & $7.20 \cdot 10^{-3} \pm 4.93 \cdot 10^{-4}$ & $-1.23 \cdot 10^{-1} \pm 1.46 \cdot 10^{-1}$ & 0.9965 \\
\hline & Cow kefir & $5-750$ & $4.91 \cdot 10^{-3} \pm 9.97 \cdot 10^{-5}$ & $-2.29 \cdot 10^{-2} \pm 2.95 \cdot 10^{-2}$ & 0.9997 & & Cow kefir & $5-750$ & $7.12 \cdot 10^{-3} \pm 1.79 \cdot 10^{-4}$ & $-7.76 \cdot 10^{-2} \pm 5.66 \cdot 10^{-2}$ & 0.9995 \\
\hline & Goat kefir & $5-750$ & $4.05 \cdot 10^{-3} \pm 1.23 \cdot 10^{-4}$ & $-8.00 \cdot 10^{-3} \pm 3.66 \cdot 10^{-2}$ & 0.9993 & & Goat kefir & $5-750$ & $1.26 \cdot 10^{-2} \pm 8.31 \cdot 10^{-4}$ & $-1.25 \cdot 10^{-1} \pm 2.56 \cdot 10^{-1}$ & 0.9967 \\
\hline \multirow[t]{4}{*}{ Formononetin } & Skimmed cheese & $5-750$ & $9.91 \cdot 10^{-4} \pm 1.07 \cdot 10^{-4}$ & $2.11 \cdot 10^{-2} \pm 3.36 \cdot 10^{-2}$ & 0.9913 & DS & Skimmed cheese & $5-750$ & $1.60 \cdot 10^{-2} \pm 4.97 \cdot 10^{-4}$ & $-1.34 \cdot 10^{-1} \pm 1.75 \cdot 10^{-1}$ & 0.9992 \\
\hline & Whole cheese & $5-750$ & $6.75 \cdot 10^{-4} \pm 2.02 \cdot 10^{-5}$ & $-3.43 \cdot 10^{-3} \pm 6.24 \cdot 10^{-3}$ & 0.9993 & & Whole cheese & $5-750$ & $1.02 \cdot 10^{-2} \pm 7.38 \cdot 10^{-4}$ & $-2.21 \cdot 10^{-1} \pm 2.34 \cdot 10^{-1}$ & 0.9960 \\
\hline & Cow kefir & $5-750$ & $1.36 \cdot 10^{-3} \pm 3.32 \cdot 10^{-5}$ & $-1.27 \cdot 10^{-2} \pm 1.05 \cdot 10^{-2}$ & 0.9995 & & Cow kefir & $5-750$ & $9.03 \cdot 10^{-3} \pm 2.55 \cdot 10^{-4}$ & $-5.62 \cdot 10^{-2} \pm 8.07 \cdot 10^{-2}$ & 0.9994 \\
\hline & Goat kefir & $5-750$ & $1.97 \cdot 10^{-3} \pm 8.21 \cdot 10^{-5}$ & $-2.19 \cdot 10^{-2} \pm 2.60 \cdot 10^{-2}$ & 0.9990 & & Goat kefir & $5-750$ & $1.35 \cdot 10^{-2} \pm 9.39 \cdot 10^{-4}$ & $-1.77 \cdot 10^{-1} \pm 2.98 \cdot 10^{-1}$ & 0.9963 \\
\hline \multirow[t]{4}{*}{ Prunetin } & Skimmed cheese & $5-750$ & $3.69 \cdot 10^{-2} \pm 3.33 \cdot 10^{-3}$ & $-5.44 \cdot 10^{-1} \pm 1.03 \cdot 10$ & 0.9940 & HEX & Skimmed cheese & $5-750$ & $2.34 \cdot 10^{-2} \pm 5.47 \cdot 10^{-4}$ & $-1.72 \cdot 10^{-1} \pm 1.73 \cdot 10^{-1}$ & 0.9996 \\
\hline & Whole cheese & $10-750$ & $7.67 \cdot 10^{-3} \pm 2.81 \cdot 10^{-4}$ & $-4.40 \cdot 10^{-2} \pm 8.68 \cdot 10^{-2}$ & 0.9990 & & Whole cheese & $5-750$ & $1.28 \cdot 10^{-2} \pm 9.54 \cdot 10^{-4}$ & $-2.26 \cdot 10^{-1} \pm 3.01 \cdot 10^{-1}$ & 0.9958 \\
\hline & Cow kefir & $15-750$ & $8.21 \cdot 10^{-3} \pm 4.16 \cdot 10^{-4}$ & $-5.83 \cdot 10^{-2} \pm 1.50 \cdot 10^{-1}$ & 0.9981 & & Cow kefir & $5-750$ & $1.52 \cdot 10^{-2} \pm 5.70 \cdot 10^{-4}$ & $-1.22 \cdot 10^{-1} \pm 1.80 \cdot 10^{-1}$ & 0.9989 \\
\hline & Goat kefir & $5-750$ & $2.69 \cdot 10^{-2} \pm 9.44 \cdot 10^{-4}$ & $-3.01 \cdot 10^{-2} \pm 3.00 \cdot 10^{-1}$ & 0.9993 & & Goat kefir & $5-750$ & $1.73 \cdot 10^{-2} \pm 1.40 \cdot 10^{-3}$ & $-1.70 \cdot 10^{-1} \pm 4.90 \cdot 10^{-1}$ & 0.9951 \\
\hline \multirow[t]{4}{*}{ Biochanin A } & Skimmed cheese & $5-750$ & $1.80 \cdot 10^{-2} \pm 1.50 \cdot 10^{-3}$ & $-3.14 \cdot 10^{-1} \pm 5.41 \cdot 10^{-1}$ & 0.9948 & $E_{3}$ & Skimmed cheese & $5-750$ & $3.47 \cdot 10^{-3} \pm 1.73 \cdot 10^{-4}$ & $-3.48 \cdot 10^{-2} \pm 5.92 \cdot 10^{-2}$ & 0.9982 \\
\hline & Whole cheese & $5-750$ & $8.17 \cdot 10^{-3} \pm 4.31 \cdot 10^{-4}$ & $-3.76 \cdot 10^{-2} \pm 1.33 \cdot 10^{-1}$ & 0.9980 & & Whole cheese & $5-750$ & $3.69 \cdot 10^{-3} \pm 3.71 \cdot 10^{-4}$ & $-7.39 \cdot 10^{-2} \pm 1.10 \cdot 10^{-1}$ & 0.9924 \\
\hline & Cow kefir & $5-750$ & $1.58 \cdot 10^{-2} \pm 1.05 \cdot 10^{-3}$ & $-5.52 \cdot 10^{-2} \pm 3.78 \cdot 10^{-1}$ & 0.9967 & & Cow kefir & $5-750$ & $3.16 \cdot 10^{-3} \pm 8.76 \cdot 10^{-5}$ & $-2.35 \cdot 10^{-2} \pm 3.06 \cdot 10^{-2}$ & 0.9994 \\
\hline & Goat kefir & $5-750$ & $1.77 \cdot 10^{-2} \pm 1.26 \cdot 10^{-3}$ & $8.20 \cdot 10^{-2} \pm 3.87 \cdot 10^{-1}$ & 0.9962 & & Goat kefir & $5-750$ & $2.63 \cdot 10^{-3} \pm 1.45 \cdot 10^{-4}$ & $-1.75 \cdot 10^{-2} \pm 4.28 \cdot 10^{-2}$ & 0.9977 \\
\hline \multirow[t]{4}{*}{$\beta-Z A L$} & Skimmed cheese & $5-750$ & $3.38 \cdot 10^{-3} \pm 2.50 \cdot 10^{-4}$ & $-2.75 \cdot 10^{-2} \pm 8.73 \cdot 10^{-2}$ & 0.9959 & $17 \beta-E_{2}$ & Skimmed cheese & $5-750$ & $2.37 \cdot 10^{-3} \pm 1.54 \cdot 10^{-4}$ & $-4.92 \cdot 10^{-2} \pm 4.87 \cdot 10^{-2}$ & 0.9968 \\
\hline & Whole cheese & $5-750$ & $2.60 \cdot 10^{-3} \pm 6.07 \cdot 10^{-5}$ & $-1.11 \cdot 10^{-2} \pm 2.02 \cdot 10^{-2}$ & 0.9997 & & Whole cheese & $5-750$ & $1.66 \cdot 10^{-3} \pm 1.61 \cdot 10^{-4}$ & $-4.20 \cdot 10^{-2} \pm 5.82 \cdot 10^{-2}$ & 0.9930 \\
\hline & Cow kefir & $10-750$ & $3.14 \cdot 10^{-3} \pm 1.07 \cdot 10^{-4}$ & $5.63 \cdot 10^{-4} \pm 3.40 \cdot 10^{-2}$ & 0.9991 & & Cow kefir & $5-750$ & $1.87 \cdot 10^{-3} \pm 8.43 \cdot 10^{-5}$ & $-3.04 \cdot 10^{-2} \pm 2.95 \cdot 10^{-2}$ & 0.9985 \\
\hline & Goat kefir & $5-750$ & $3.08 \cdot 10^{-3} \pm 1.35 \cdot 10^{-4}$ & $-2.60 \cdot 10^{-2} \pm 4.15 \cdot 10^{-2}$ & 0.9986 & & Goat kefir & $5-750$ & $2.12 \cdot 10^{-3} \pm 1.44 \cdot 10^{-4}$ & $-4.45 \cdot 10^{-2} \pm 4.55 \cdot 10^{-2}$ & 0.9965 \\
\hline \multirow[t]{4}{*}{$\beta-Z E L$} & Skimmed cheese & $5-750$ & $1.69 \cdot 10^{-3} \pm 8.48 \cdot 10^{-5}$ & $-1.84 \cdot 10^{-2} \pm 2.51 \cdot 10^{-2}$ & 0.9977 & $17 \alpha-E_{2}$ & Skimmed cheese & $5-750$ & $3.24 \cdot 10^{-3} \pm 1.40 \cdot 10^{-4}$ & $-5.56 \cdot 10^{-2} \pm 4.93 \cdot 10^{-2}$ & 0.9986 \\
\hline & Whole cheese & $5-750$ & $1.22 \cdot 10^{-3} \pm 2.06 \cdot 10^{-5}$ & $2.06 \cdot 10^{-3} \pm 6.51 \cdot 10^{-3}$ & 0.9998 & & Whole cheese & $5-750$ & $2.02 \cdot 10^{-3} \pm 1.87 \cdot 10^{-4}$ & $-5.54 \cdot 10^{-2} \pm 5.54 \cdot 10^{-2}$ & 0.9936 \\
\hline & Cow kefir & $10-750$ & $1.25 \cdot 10^{-3} \pm 6.81 \cdot 10^{-5}$ & $-1.38 \cdot 10^{-2} \pm 2.46 \cdot 10^{-2}$ & 0.9978 & & Cow kefir & $5-750$ & $2.14 \cdot 10^{-3} \pm 1.53 \cdot 10^{-4}$ & $-4.37 \cdot 10^{-2} \pm 4.84 \cdot 10^{-2}$ & 0.9961 \\
\hline & Goat kefir & $5-750$ & $1.60 \cdot 10^{-3} \pm 6.45 \cdot 10^{-5}$ & $-4.61 \cdot 10^{-3} \pm 1.99 \cdot 10^{-2}$ & 0.9988 & & Goat kefir & $5-750$ & $2.48 \cdot 10^{-3} \pm 1.29 \cdot 10^{-4}$ & $-3.16 \cdot 10^{-2} \pm 3.98 \cdot 10^{-2}$ & 0.9980 \\
\hline \multirow{4}{*}{$\alpha-\mathrm{ZAL}$} & Skimmed cheese & $1-750$ & $6.96 \cdot 10^{-3} \pm 3.34 \cdot 10^{-4}$ & $-5.84 \cdot 10^{-2} \pm 1.02 \cdot 10^{-1}$ & 0.9983 & $\mathrm{E}_{1}$ & Skimmed cheese & $5-750$ & $1.66 \cdot 10^{-2} \pm 3.74 \cdot 10^{-4}$ & $-1.26 \cdot 10^{-1} \pm 1.31 \cdot 10^{-1}$ & 0.9996 \\
\hline & Whole cheese & $5-750$ & $3.65 \cdot 10^{-3} \pm 1.89 \cdot 10^{-4}$ & $-2.67 \cdot 10^{-2} \pm 5.82 \cdot 10^{-2}$ & 0.9980 & & Whole cheese & $5-750$ & $1.03 \cdot 10^{-2} \pm 9.87 \cdot 10^{-4}$ & $-2.40 \cdot 10^{-1} \pm 3.13 \cdot 10^{-1}$ & 0.9931 \\
\hline & Cow kefir & $10-750$ & $4.87 \cdot 10^{-3} \pm 8.45 \cdot 10^{-5}$ & $2.94 \cdot 10^{-2} \pm 2.97 \cdot 10^{-2}$ & 0.9998 & & Cow kefir & $5-750$ & $1.13 \cdot 10^{-1} \pm 6.14 \cdot 10^{-4}$ & $-1.40 \cdot 10^{-1} \pm 2.16 \cdot 10^{-1}$ & 0.9978 \\
\hline & Goat kefir & $5-750$ & $4.18 \cdot 10^{-3} \pm 2.76 \cdot 10^{-4}$ & $4.21 \cdot 10^{-2} \pm 8.71 \cdot 10^{-2}$ & 0.9967 & & Goat kefir & $5-750$ & $1.07 \cdot 10^{-2} \pm 5.05 \cdot 10^{-4}$ & $-6.92 \cdot 10^{-2} \pm 1.49 \cdot 10^{-1}$ & 0.9983 \\
\hline
\end{tabular}


Table 4

Results of the recovery study $(n=5)$ of the QuEChERS-UHPLC-MS/MS method for the selected compounds in the different matrices at three levels of concentration.

\begin{tabular}{|c|c|c|c|c|c|c|c|c|c|c|c|}
\hline Analyte & Type of matrix & $\begin{array}{l}\text { Level 1a } \\
(\mathrm{n}=5) \\
\text { Recovery\% } \\
(\mathrm{RSD}, \%)\end{array}$ & $\begin{array}{l}\text { Level } 2^{\mathrm{b}} \\
(\mathrm{n}=5) \\
\text { Recovery\% } \\
(\mathrm{RSD}, \%)\end{array}$ & $\begin{array}{l}\text { Level 3c } \\
(\mathrm{n}=5) \\
\text { Recovery\% } \\
(\mathrm{RSD}, \%)\end{array}$ & $\begin{array}{l}\text { LOQ }_{\text {method }}{ }^{d} \\
(\mu \mathrm{kg})\end{array}$ & Analyte & Type of matrix & $\begin{array}{l}\text { Level } 1^{\mathrm{a}} \\
(\mathrm{n}=5) \\
\text { Recovery\% } \\
(\mathrm{RSD}, \%)\end{array}$ & $\begin{array}{l}\text { Level } 2^{\mathrm{b}} \\
(\mathrm{n}=5) \\
\text { Recovery\% } \\
(\mathrm{RSD}, \%)\end{array}$ & $\begin{array}{l}\text { Level 3c } \\
(\mathrm{n}=5) \\
\text { Recovery\% } \\
(\mathrm{RSD}, \%)\end{array}$ & $\begin{array}{l}\text { LOQmethod }^{\mathrm{d}} \\
(\mu \mathrm{g} / \mathrm{kg})\end{array}$ \\
\hline \multirow[t]{4}{*}{ Daidzein } & Skimmed cheese & $109(5)$ & $94(10)$ & $92(4)$ & 0.025 & $\alpha$-ZEL & Skimmed cheese & $96(8)$ & $112(8)$ & $93(8)$ & 0.250 \\
\hline & Whole cheese & $109(8)$ & $84(6)$ & $90(3)$ & 0.050 & & Whole cheese & $83(11)$ & $83(9)$ & $80(2)$ & 0.250 \\
\hline & Cow kefir & $119(13)$ & $119(4)$ & $114(7)$ & 0.050 & & Cow kefir & $93(11)$ & $73(5)$ & $94(7)$ & 0.250 \\
\hline & Goat kefir & $100(8)$ & $103(3)$ & $99(5)$ & 0.050 & & Goat kefir & $91(4)$ & $78(11)$ & $80(4)$ & 0.500 \\
\hline \multirow[t]{4}{*}{ Enterodiol } & Skimmed cheese & $97(10)$ & $94(9)$ & $91(4)$ & 0.250 & ZAN & Skimmed cheese & $78(9)$ & $119(4)$ & $99(8)$ & 0.250 \\
\hline & Whole cheese & $90(14)$ & $80(6)$ & $90(7)$ & 0.250 & & Whole cheese & $84(9)$ & $78(6)$ & $88(8)$ & 0.250 \\
\hline & Cow kefir & $103(6)$ & $93(8)$ & $99(5)$ & 0.500 & & Cow kefir & $111(9)$ & $74(6)$ & $84(8)$ & 2.50 \\
\hline & Goat kefir & $107(1)$ & $84(6)$ & $91(8)$ & 0.250 & & Goat kefir & $110(7)$ & $86(6)$ & $84(5)$ & 0.250 \\
\hline \multirow[t]{4}{*}{ Glycitein } & Skimmed cheese & $102(9)$ & $100(8)$ & $101(3)$ & 0.050 & ZEN & Skimmed cheese & $97(10)$ & $116(3)$ & $112(9)$ & 0.050 \\
\hline & Whole cheese & $106(6)$ & $81(6)$ & $90(7)$ & 0.250 & & Whole cheese & $98(15)$ & $71(3)$ & $78(3)$ & 0.250 \\
\hline & Cow kefir & $98(11)$ & $109(10)$ & $97(7)$ & 0.500 & & Cow kefir & $93(7)$ & $77(9)$ & $82(5)$ & 0.250 \\
\hline & Goat kefir & $106(7)$ & $96(6)$ & $101(8)$ & 0.500 & & Goat kefir & $102(9)$ & $76(8)$ & $55(8)$ & 0.250 \\
\hline \multirow[t]{4}{*}{ Enterolactone } & Skimmed cheese & $109(10)$ & $115(7)$ & $110(2)$ & 0.050 & $\mathrm{EE}_{2}$ & Skimmed cheese & $80(6)$ & $102(8)$ & $103(6)$ & 0.250 \\
\hline & Whole cheese & $98(7)$ & $119(7)$ & $113(10)$ & 0.250 & & Whole cheese & $97(6)$ & $90(12)$ & $102(9)$ & 0.250 \\
\hline & Cow kefir & $108(6)$ & $118(6)$ & $106(10)$ & 0.250 & & Cow kefir & $93(7)$ & $92(8)$ & $88(8)$ & 0.500 \\
\hline & Goat kefir & $109(11)$ & $112(6)$ & $78(11)$ & 0.250 & & Goat kefir & $85(13)$ & $100(9$ & $87(4)$ & 0.250 \\
\hline \multirow[t]{4}{*}{ Genistein } & Skimmed cheese & $109(8)$ & $98(9)$ & $92(2)$ & 0.050 & DES & Skimmed cheese & $87(9)$ & $86(7)$ & $97(10)$ & 0.250 \\
\hline & Whole cheese & $102(6)$ & $78(6)$ & $82(4)$ & 0.250 & & Whole cheese & $105(5)$ & $108(9)$ & $86(9)$ & 0.250 \\
\hline & Cow kefir & $100(9)$ & $107(12)$ & $108(11)$ & 0.250 & & Cow kefir & $101(10)$ & $80(7)$ & $79(6)$ & 0.250 \\
\hline & Goat kefir & $100(8)$ & $118(8)$ & $82(8)$ & 0.250 & & Goat kefir & $81(8)$ & $83(6)$ & $91(8)$ & 0.250 \\
\hline \multirow[t]{4}{*}{ Formononetin } & Skimmed cheese & $88(9)$ & $96(15)$ & $92(4)$ & 0.250 & DS & Skimmed cheese & $85(9)$ & $90(9)$ & $107(2)$ & 0.250 \\
\hline & Whole cheese & $87(10)$ & $70(3)$ & $77(12)$ & 0.250 & & Whole cheese & $86(7)$ & $97(10)$ & $83(9)$ & 0.250 \\
\hline & Cow kefir & $103(10)$ & $103(9)$ & $100(10)$ & 0.250 & & Cow kefir & $88(4)$ & $81(6)$ & $75(6)$ & 0.250 \\
\hline & Goat kefir & $112(9)$ & $112(9)$ & $74(8)$ & 0.250 & & Goat kefir & $81(14)$ & $88(3)$ & $84(5)$ & 0.250 \\
\hline \multirow[t]{4}{*}{ Prunetin } & Skimmed cheese & $99(7)$ & $90(9)$ & $96(8)$ & 0.250 & HEX & Skimmed cheese & $100(5)$ & $108(5)$ & $114(2)$ & 0.250 \\
\hline & Whole cheese & $79(11)$ & $76(5)$ & $70(5)$ & 0.500 & & Whole cheese & $75(9)$ & $106(7)$ & $93(9)$ & 0.250 \\
\hline & Cow kefir & 77 (10) & $77(4)$ & $86(7)$ & 0.750 & & Cow kefir & $109(5)$ & $96(8)$ & $81(6)$ & 0.250 \\
\hline & Goat kefir & $102(8)$ & $94(3)$ & $78(4)$ & 0.250 & & Goat kefir & $84(13)$ & $101(4)$ & $95(4)$ & 0.250 \\
\hline \multirow[t]{4}{*}{ Biochanin A } & Skimmed cheese & $97(6)$ & $89(8)$ & $92(10)$ & 0.250 & $E_{3}$ & Skimmed cheese & $109(10)$ & $96(9)$ & $103(13)$ & 0.250 \\
\hline & Whole cheese & $78(4)$ & $82(9)$ & $92(10)$ & 0.250 & & Whole cheese & $89(12)$ & $97(4)$ & $85(8)$ & 0.250 \\
\hline & Cow kefir & $94(5)$ & $83(3)$ & $85(4)$ & 0.250 & & Cow kefir & $102(6)$ & $119(7)$ & $105(6)$ & 0.250 \\
\hline & Goat kefir & $105(14)$ & $71(11)$ & $76(6)$ & 0.250 & & Goat kefir & $96(14)$ & $100(4)$ & $96(2)$ & 0.250 \\
\hline \multirow[t]{4}{*}{$\beta-\mathrm{ZAL}$} & Skimmed cheese & $90(7)$ & $112(6)$ & $92(2)$ & 0.250 & $17 \beta-E_{2}$ & Skimmed cheese & $92(8)$ & $114(6)$ & $94(9)$ & 0.250 \\
\hline & Whole cheese & $94(11)$ & $92(1)$ & $84(3)$ & 0.250 & & Whole cheese & $92(10)$ & $80(10)$ & $84(13)$ & 0.250 \\
\hline & Cow kefir & $98(10)$ & $99(6)$ & $99(6)$ & 0.500 & & Cow kefir & $77(9)$ & $93(6)$ & $96(8)$ & 0.250 \\
\hline & Goat kefir & $86(10)$ & $103(5)$ & $94(3)$ & 0.250 & & Goat kefir & $95(9)$ & $86(9)$ & $91(4)$ & 0.250 \\
\hline \multirow[t]{4}{*}{$\beta$-ZEL } & Skimmed cheese & $98(8)$ & $111(8)$ & $89(3)$ & 0.250 & $17 \alpha-E_{2}$ & Skimmed cheese & $107(9)$ & $110(5)$ & $100(8)$ & 0.250 \\
\hline & Whole cheese & $84(10)$ & $71(3)$ & $81(4)$ & 0.250 & & Whole cheese & $81(11)$ & $95(12)$ & $93(12)$ & 0.250 \\
\hline & Cow kefir & $73(4)$ & $93(10)$ & $99(6)$ & 0.500 & & Cow kefir & $99(6)$ & $103(10)$ & $97(5)$ & 0.250 \\
\hline & Goat kefir & $78(9)$ & $81(11)$ & $76(6)$ & 0.250 & & Goat kefir & $96(4)$ & $89(6)$ & $92(3)$ & 0.250 \\
\hline \multirow[t]{4}{*}{$\alpha-Z A L$} & Skimmed cheese & $84(10)$ & $106(9)$ & $97(6)$ & 0.050 & $\mathrm{E}_{1}$ & Skimmed cheese & $112(6)$ & $107(3)$ & $101(8)$ & 0.250 \\
\hline & Whole cheese & $90(8)$ & $78(5)$ & $71(5)$ & 0.250 & & Whole cheese & $96(9)$ & $100(6)$ & $91(5)$ & 0.250 \\
\hline & Cow kefir & $102(11)$ & $90(9)$ & $106(8)$ & 0.500 & & Cow kefir & $96(5)$ & $109(9)$ & $99(5)$ & 0.250 \\
\hline & Goat kefir & $100(4)$ & $89(1)$ & $109(9)$ & 0.250 & & Goat kefir & $85(10)$ & $103(2)$ & $99(3)$ & 0.250 \\
\hline
\end{tabular}

${ }^{a}$ Concentrations of the analytes in the samples: $1.88 \mu \mathrm{g} / \mathrm{kg}$ except in cow kefir where they were $4 \mu \mathrm{g} / \mathrm{kg}$ for ZAN and $2.56 \mu \mathrm{g} / \mathrm{kg}$ for natural and synthetic estrogens and formononetin and prunetin

b Concentrations of the analytes in the samples: $17.5 \mu \mathrm{g} / \mathrm{kg}$.

c Concentrations of the analytes in the samples: $37.5 \mu \mathrm{g} / \mathrm{kg}$.

d Defined as the lowest matrix matched calibration concentration which provided a signal noise ratio higher than 10 for the quantification transition and at least 3 for the confirmation transition (if it was available). 

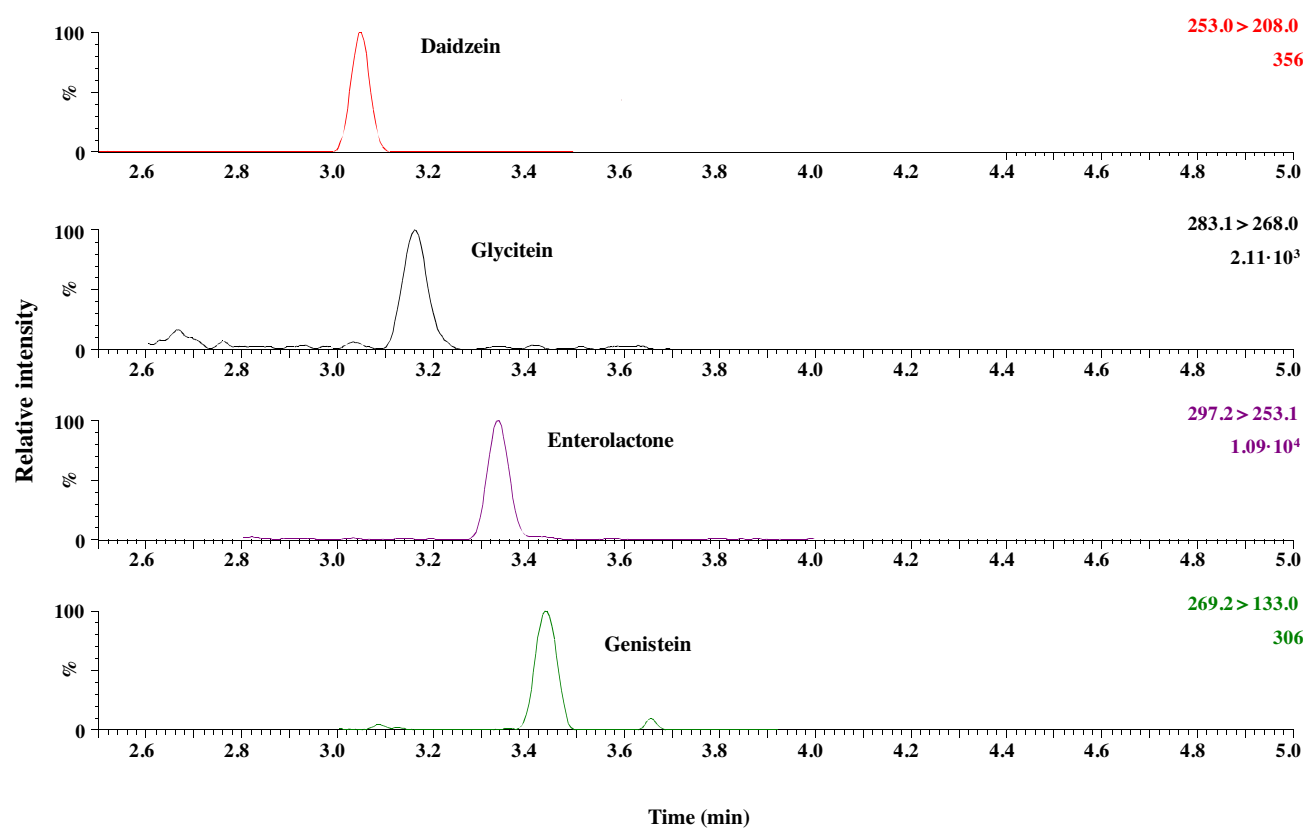

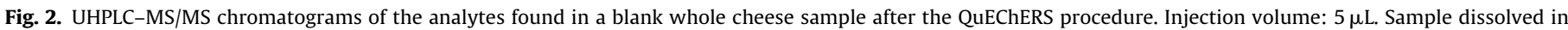
$500 \mu \mathrm{L}$ of $50 / 50(\mathrm{v} / \mathrm{v}) \mathrm{MeOH} /$ water. Separation at $40^{\circ} \mathrm{C}$.

Table 5

Analysis of real samples using the developed QuEChERS-UHPLC-MS/MS method.

\begin{tabular}{|c|c|c|c|c|c|c|c|c|}
\hline \multirow[t]{2}{*}{ Analytes } & \multicolumn{8}{|c|}{ Concentration of analyte $(\mu \mathrm{g} / \mathrm{kg})^{\mathrm{a}, \mathrm{b}}$} \\
\hline & SC1 & SC2 & WC1 & WC2 & CK1 & CK2 & GK1 & GK2 \\
\hline Daidzein & $1.8 \pm 0.9$ & $3.3 \pm 0.9$ & $<\mathrm{LOQ}$ & $<\mathrm{LOQ}$ & n.d. & n.d. & $<$ LOQ & $4.8 \pm 1.3$ \\
\hline Glycitein & $13.6 \pm 0.4$ & $25.1 \pm 0.5$ & $1.9 \pm 0.8$ & $3.4 \pm 0.8$ & n.d. & n.d. & $5.9 \pm 1.4$ & $11.4 \pm 1.4$ \\
\hline Enterolactone & $34.7 \pm 0.7$ & $46.7 \pm 0.8$ & $23.3 \pm 1.0$ & $24.5 \pm 1.1$ & $8.8 \pm 0.2$ & n.d. & $<\mathrm{LOQ}$ & $4.0 \pm 1.1$ \\
\hline Genistein & $<\mathrm{LOQ}$ & $<\mathrm{LOQ}$ & $<\mathrm{LOQ}$ & $<\mathrm{LOQ}$ & n.d. & n.d. & $<\mathrm{LOQ}$ & $1.1 \pm 0.6$ \\
\hline
\end{tabular}

a Results obtained as an average of two analyses for each product.

b n.d.: not detected. SC: skimmed cheese; WC: whole cheese; CK: cow kefir; GC: goat kefir.

four natural estrogens prior their determination by UHPLC-MS/MS obtaining LOQs in the range $0.77-237 \mu \mathrm{g} / \mathrm{kg}$, while in the article reported by our group [17] a HF-LPME-HPLC-DAD/FD method was applied for the determination of four natural and four synthetic estrogens in $3 \mathrm{~g}$ of cheese samples using octanol as extraction solvent and resulting LOQs from 2.3 to $5.4 \mu \mathrm{g} / \mathrm{kg}$. With respect to phytoestrogens analysis, Kuhnle et al. [6] applied a LLE using $2 \mathrm{~mL}$ of $\mathrm{MeOH}$ in sodium acetate to $100 \mathrm{mg}$ of sample followed by a hydrolysis with $\beta$-glucuronidase $/ \alpha$-glucosidase and a SPE in $C_{18}$ cartridges for the determination of twelve phytoestrogens by HPLCQTrap-MS/MS, obtaining a LOQ for all analytes of $50 \mu \mathrm{g} / \mathrm{kg}$. Kř̌ižová et al. [7] used the same hydrolysis reactant and ethyl acetate for the LLE of four phytoestrogens from cheese samples prior their analysis by HPLC-IT-MS/MS. In this case the LOQs were around 6-17 $\mu \mathrm{g} / \mathrm{kg}$. As can be seen, LOQs preciously obtained are considerably higher than the ones achieved in this work for cheese (between 0.025 and $0.50 \mu \mathrm{g} / \mathrm{kg}$ ) which demonstrates the great sensitivity of the developed methodology and their suitable application for the analysis of estrogenic compounds whose occurrence has been reported at very low concentration in dairy products $[1,6]$.

\section{Conclusions}

In this work, a methodology based on the analysis by UHPLCQqQ-MS/MS after the application of the QuEChERS method has been applied for the determination of a group of 22 endocrine disruptors including 8 phytoestrogens, 6 mycoestrogens as well as 4 natural and 4 synthetic estrogens in complex dairy products sam- ples such as skimmed and whole cheese and kefir with cow and goat origin. Validation of the whole method was carried out in terms of matrix effect, linearity, repeatability and reproducibility obtaining excellent results as well as recovery values in the range 70-119\% and low LOQs (between 0.025 and $0.50 \mu \mathrm{g} / \mathrm{kg}$ for cheese and between 0.05 and $2.5 \mu \mathrm{g} / \mathrm{kg}$ for kefir samples). The developed procedure constitutes an environmental friendly method which combines the advantages that QuEChERS extraction provides in terms of simplicity and low cost, together with the great specificity, reproducibility and sensitivity of the UHPLC-QqQ-MS/MS system to determine the selected estrogenic compounds. According to the good results obtained, the methodology was successfully applied for the analysis of real samples finding the presence of some phytoestrogens in the majority of the analyzed products. Therefore, this method presents a clear alternative for the determination of this group of endocrine disruptors in very complex samples in which their determination and control presents a great relevance due to the hormonal disorders and diseases that can produce in consumers of this type of commercial products.

\section{Acknowledgements}

B.S.R. would like to thank the Canary Agency of Economy, Industry, Trade and Knowledge of the Government of the Canary Islands for the FPI fellowship (co-financed with an 85\% from European Social Funds). This work has been supported by the Spanish Ministry of Economy and Competitiveness (project AGL2011-24667). 


\section{Appendix A. Supplementary data}

Supplementary data associated with this article can be found, in the online version, at http://dx.doi.org/10.1016/j.chroma.2017.03. 034.

\section{References}

[1] B. Socas-Rodríguez, M. Asensio-Ramos, A.V. Herrera-Herrera, J. Hernández-Borges, M.Á. Rodríguez-Delgado, Chromatographic analysis of natural and synthetic estrogens in milk and dairy products, TrAC Trend. Anal. Chem. 44 (2013) 58-77.

[2] B. Shao, R. Zhao, J. Meng, Y. Xue, G. Wu, J. Hu, X. Tu, Simultaneous determination of residual hormonal chemicals in meat, kidney, liver tissues and milk by liquid chromatography-tandem mass spectrometry, Anal. Chim. Acta 548 (2005) 41-50.

[3] M. Mei, J. Yu, X. Huang, H. Li, L. Lin, D. Yuan, Monitoring of selected estrogen mimics in complicated samples using polymeric ionic liquid-based multiple monolithic fiber solid-phase microextraction combined with high-performance liquid chromatography, J. Chromatogr. A 1385 (2015) 12-19.

[4] L.K. Sørensen, T.H. Elbæk, Determination of mycotoxins in bovine milk by liquid chromatography tandem mass spectrometry, J. Chromatogr. B 820 (2005) 183-196.

[5] A.L. Capriotti, C. Cavaliere, S. Piovesana, S. Stampachiacchiere, R. Samperi, S. Ventura, A. Lagana; Simultaneous determination of naturally occurring estrogens and mycoestrogens in milk by ultra high-performance liquid chromatography-tandem mass spectrometry analysis, J. Agric. Food Chem. 63 (2015) 8940-8946.

[6] G.G.C. Kuhnle, C. Dell'Aquila, S.M. Aspinall, S.A. Runswick, A.A. Mulligan, S.A. Bingham, Phytoestrogen content of foods of animal origin: dairy products, eggs, meat, fish, and seafood, J. Agric. Food Chem. 56 (2008) 10099-10104.

[7] L. Kř́ížová, A. Veselý, J. Třináctý, V. Schulzová, A. Hurajová, J. Hajšlová, E. Kvasničková, Š. Havlíková, Changes in isoflavones concentrations in cheese during processing and ripening, Acta Univ. Agric. Silvic. 59 (2011) 153-162.

[8] Directive 2003/74/EC of the European Parliament and of the Council of 22 September 2003 amending Council Directive 96/22/EC concerning the prohibition on the use in stock farming of certain substances having a hormonal or thyrostatic action and of beta-agonists, Off. J. Eur. Union 14.10.2003, L262/17.

[9] Council Directive 96/22/EC of 29 April 1996 on measures to monitor certain substances and residues thereof in live animals and animal products and repealing Directives 85/358/EEC and 86/469/EEC and Decisions 89/187/EEC and 91/664/EEC, Off. J. Eur. Commun. 23.05.96, L125/10.

[10] W.N. Jefferson, H.B. Patisaul, C.J. Williams, Reproductive consequences of developmental phytoestrogen exposure, Reproduction 143 (2012) 247-260.

[11] A.L. Capriotti, C. Cavaliere, V. Colapicchioni, S. Piovesana, R. Samperi, A. Laganà, Analytical strategies based on chromatography-mass spectrometry for the determination of estrogen-mimicking compounds in food, J. Chromatogr. A 1313 (2013) 62-77.

[12] J. Aufartová, C. Mahugo-Santana, Z. Sosa-Ferrera, J.J. Santana-Rodríguez, L. Nováková, P. Solich, Determination of steroid hormones in biological and environmental samples using green microextraction techniques: an overview, Anal. Chim. Acta 704 (2011) 33-46.

[13] P.W. Parodi, Impact of cows' milk estrogen on cancer risk, Int. Dairy J. 22 (2012) 3-14.

[14] A.E. Fayed, Review article: health benefits of some physiologically active ingredients and their as yoghurt fortifiers, J. Food Sci. Technol. 52 (2015) 2512-2521.

[15] A.D. Lafleur, K.A. Schug, A review of separation methods for the determination of estrogens and plastics-derived estrogen mimics from aqueous systems, Anal. Chim. Acta 696 (2011) 6-26.

[16] H. Lan, N. Gan, D. Pan, F. Hu, T. Li, N. Long, L. Qiao, An automated solid-phase microextraction method based on magnetic molecularly imprinted polymer as fiber coating for detection of trace estrogens in milk powder, J. Chromatogr. A 1331 (2014) 10-18.

[17] B. Socas-Rodríguez, M. Asensio-Ramos, J. Hernández-Borges, M.Á. Rodríguez-Delgado, Analysis of oestrogenic compounds in dairy products by hollow-fibre liquid-phase microextraction coupled to liquid chromatography, Food Chem. 149 (2014) 319-325.
[18] C. Cavaliere, A.L. Capriotti, P. Foglia, S. Piovesana, R. Samperi, S. Ventura, A. Lagana, Natural estrogens in dairy products: determination of free and conjugated forms by ultra high performance liquid chromatography with tandem mass spectrometry, J. Sep. Sci. 38 (2015) 3599-3606.

[19] G. Li, L. Dong, A. Wang, W. Wang, N. Hu, J. You, Simultaneous determination of biogenic amines and estrogens in foodstuff by an improved HPLC method combining with fluorescence labelling, LWT Food Sci. Technol. 55 (2014) 355-361.

[20] M. Anastassiades, S.J. Lehotay, D. Štajnbaher, F.J. Schenck, Fast and easy multiresidue method employing acetonitrile extraction/partitioning and dispersive solid-phase extraction for the determination of pesticide residues in produce, J. AOAC Int. 86 (2003) 412-431.

[21] J. Naícher-Mestre, R. Serrano, T. Portoleís, M.H.G. Berntssen, J. Peírez-Saínchez, F. Hernaíndez, Screening of pesticides and polycyclic aromatic hydrocarbons in feeds and fish tissues by gas chromatography coupled to high-resolution mass spectrometry using atmospheric pressure chemical ionization, J. Agric. Food Chem. 62 (2014) 2165-2174.

[22] W. Peysson, E. Vulliet, Determination of 136 pharmaceuticals and hormones in sewage sludge using quick, easy, cheap, effective, rugged and safe extraction followed by analysis with liquid chromatography-time-of-flight-mass spectrometry, J. Chromatogr. A 1290 (2013) 46-61.

[23] H.R. Norli, A. Christiansen, E. Deribe, Application of QuEChERS method for extraction of selected persistent organic pollutants in fish tissue and analysis by gas chromatography mass spectrometry, J. Chromatogr. A 1218 (2011) 7234-7241.

[24] T.V. Madureira, S. Velhote, C. Santos, C. Cruzeiro, E. Rocha, M.J. Rocha, A step forward using QuEChERS (Quick, Easy, Cheap, Effective, Rugged, and Safe) based extraction and gas chromatography-tandem mass spectrometry-levels of priority polycyclic aromatic hydrocarbons in wild and commercial mussels, Environ. Sci. Pollut. R 21 (2014) 6089-6098.

[25] H. Li, J. Yin, Y. Liu, J. Shang, Effect of protein on the detection of fluoroquinolone residues in fish meat, J. Agric. Food Chem. 60 (2012) 1722-1727.

[26] S. Ehling, T.M. Reddy, Liquid chromatography-mass spectrometry method for the quantitative determination of residues of selected veterinary hormones in powdered ingredients derived from bovine milk, J. Agric. Food Chem. 61 (2013) 11782-11791

[27] J. Rubert, N. León, C. Sáez, C.P.B. Martins, M. Godula, V. Yusà, J. Mañes, J.M. Soriano, C. Soler, Evaluation of mycotoxins and their metabolites in human breast milk using liquid chromatography coupled to high resolution mass spectrometry, Anal. Chim. Acta 820 (2014) 39-46.

[28] W. Jia, X. Chu, Y. Ling, J. Huang, J. Chang, Multi-mycotoxin analysis in dairy products by liquid chromatography coupled to quadrupole orbitrap mass spectrometry, J. Chromatogr. A 1345 (2014) 107-114.

[29] B. Socas-Rodríguez, D. Lanková, K. Urbancová, V. Krtková, J. Hernández-Borges, M.Á. Rodríguez-Delgado, J. Hajšlová, Multiclass analytical method for the determination of natural/synthetic steroid hormones, phytoestrogens and mycoestrogens in milk and yogurt, (submitted).

[30] European Commission, Decision 2002/657/EC of 12 August 2002 implementing Council Directive 96/23/EC concerning the performance of analytical methods and the interpretation of results. Off. J. Eur. Union L221 (2002) 8-36.

[31] D. Lanková, O. Lacina, J. Pulkrabová, J. Hajšlová, The determination of perfluoroalkyl substances, brominated flame retardants and their metabolites in human breast milk and infant formula, Talanta 117 (2013) 318-325.

[32] K. Koot, B. Zawisza, E. Marguí, I. Queralt, M. Hidalgo, R. Sitko, Dispersive micro solid-phase extraction using multiwalled carbon nanotubes combined with portable total-reflection X-ray fluorescence spectrometry for the determination of trace amounts of $\mathrm{Pb}$ and $\mathrm{Cd}$ in water samples, J. Anal. At. Spectrom. 28 (2013) 736-742.

[33] X.-H. Chen, L.-X. Zhou, Y.-G. Zhao, S.-D. Pan, M.-C. Jin, Application of nano ring amino-functionalized magnetic polymer dispersive micro-solid-phase extraction and ultra fast liquid chromatography-tandem mass spectrometry in dicyandiamide residue analysis of powdered milk, Talanta 119 (2014) $187-192$.

[34] B.K. Matuszewski, M.L. Constanzer, C.M. Chavez-Eng, Strategies for the assessment of matrix effect in quantitative bioanalytical methods based on HPLC-MS/MS, Anal. Chem. 75 (2003) 3019-3030. 